\title{
Cooperative Management of Ecosystem Services: Coalition Formation, Landscape Structure and Policies
}

\author{
Francois Bareille $^{1,2}$ (D) Matteo Zavalloni ${ }^{1}$ (D) Meri Raggi ${ }^{1}$ (D) Davide Viaggi ${ }^{1}$ (D)
}

Accepted: 21 April 2021 / Published online: 13 May 2021

(c) The Author(s) 2021

\begin{abstract}
A growing body of literature shows that full-cooperation among farmers to manage productive ecosystem services would yield gains with respect to uncoordinated approaches. The public good feature of these ecosystem services may, however, hinder the emergence of a cooperative solution at the landscape scale. In this paper, we introduce in a coalition formation game a spatially-explicit bioeconomic model of fruit pollination, where pollinaton depends on the distance to the choosen location of natural habitats. We analyse: (i) which coalitions are stable; (ii) what benefits they provide; (iii) how cooperation depends on the initial landscape structure; and (iv) how policy instruments affect cooperation. The theoretical model presents the rationality of cooperation but, due to the detailed heterogeneity and complex spatial interactions among farms, we use a numerical example to determine the stable coalitions. We find that only small coalitions are stable and that the benefits of cooperation decrease when the spatial autocorrelation of fruit tree covers increase. Policy instruments can increase the interest for cooperation but per-hectare payments and minimum participation rules may reduce the habitat area at the margin (by decreasing the stability of coalitions). Price premium for the coalition members increase the habitat area but its budget-effectiveness decreases as the spatial autocorrelation of fruit tree covers increase.
\end{abstract}

Keywords Agri-environmental policy · Biodiversity · Collective incentives · Externalities · Pollinators $\cdot$ Spatially explicit spillovers

\section{Introduction}

The conservation of biodiversity and related ecosystem services (ES) depends on the structure of landscapes (e.g., density and spatial autocorrelation of natural habitats), which are the results of landowners' land-use decisions (Haines-Young and Potschin 2010). While biodiversity conservation benefits society as a whole (Hanley et al. 2015), some of the related ES, such as biological control or pollination, are central for agricultural production

Francois Bareille

francois.bareille@inrae.fr

1 Department of Agricultural and Food Sciences, University of Bologna, Bologna, Italy

2 Economie Publique, AgroParisTech, INRAE, Paris-Saclay University, Thiverval-Grignon, France 
(Albrecht et al. 2020). The economic importance of these productive ES is increasingly acknowledged: for example, the French ecosystem assessment estimates that pollinators contribute between $5.2 \%$ and $12 \%$ of the total crop value (Therond et al. 2017). The literature suggests that farmers can integrate the impacts of their land-use choices on productive ES to manage them efficiently, i.e. to benefit from additional yields or input-savings (Zhang et al. 2007). Some microeconometric studies have suggested that farmers do integrate these effects at the farm scale (Bareille and Letort 2018; Orazem and Miranowski 1994; Thomas 2003).

Since the provision of many productive ES depends on mobile "ES providers", such as pollinators or pest-predatory insects, farmers' land-use choices may, however, create positive externalities for neighbouring farmers (Bareille et al. 2020; Costello et al. 2017). In this context, cooperation among farmers to manage productive ES is likely to be an efficient strategy for farmers. Some real-world examples of such cooperative management exist, ${ }^{1}$ in particular with regard to the management of pollination service. Since pollination service is a local public good, farmers also face well-known free-riding issues: even if the coordinated management of productive ES among farmers should lead to Pareto improvements, its emergence is unikely to occur. Simulations based on bioeconomic models show that, indeed, the cooperation of all farmers in a landscape (i.e. the Grand Coalition - GC) yields Pareto improvements with respect to the uncoordinated ES management (the Nash Equilibrium - NE), but that at least some farmers have incentives to defect (Cong et al. 2014; Epanchin-Niell and Wilen 2015). These incentives are even more pronounced when farmers are heterogeneous (Atallah et al. 2017; Bareille et al. 2020). However, these papers only compare the outcomes of the NE with those of the GC, neglecting the possible subgroups of, for example 2 or 3 farmers, which can be formed within a population of $\mathrm{N}$ farmers $(\mathrm{N}>3)$. In his seminal paper, Olson (1965) though postulated that small groups would be more likely to cooperate as the free-riding problem they face is less signficant.

The literature on coalition formation offers a structure to endogenize the individual decision of a farmer to cooperate (Barrett 1994; d'Aspremont et al. 1983). The idea behind this literature is that any coalition is feasible in principle (not only the GC or the singletons constituting the NE), but that only the stable ones can emerge. A coalition is stable when no members have incentives to exit (or deviate from the coalition's optimum) and nonmembers have no incentives to enter. This type of game has been used intensively for the analysis of international environmental agreements targetting the provision of global public goods (Barrett 1994; Bayramoglu et al. 2018; Carraro and Siniscalco 1993) but also of the cooperation amongst firms on R\&D investments (Bloch 1995) or on voluntary agreements among firms (Brau and Carraro 2011). More recently, it has been used to assess

\footnotetext{
1 For example, the "GIEE" are groups of farms recognised by France to manage natural resources in common. They receive additional subsidies from European, National or Regional programs. There are about 500 GIEE in France, with an average size of twenty farmers (Source: https://agriculture.gouv.fr/pres-de10-000-agriculteurs-engages-dans-les-groupements-dinteret-economique-et-environnemental-giee [last read on 02/24/2021]). Further, many French winegrowers manage in common the flavescence dorée, a common pest for wineyards, in groups organised at the province scale (Constant and Lernould, 2014). Finally, some French farmers manage pollination services in common by planting hedgerows in key localizations to provide habitats for wild pollinators across the landscape. Information obtained from the French regional press; article available (in French) at: https://www.lepopulaire.fr/saint-junien-87200/actualites/des-agric ulteurs-de-haute-vienne-plantent-des-haies-pour-les-abeilles-et-les-pollinisateurs_13730348/ [last read on 02/24/2021].
} 
the performance of collective incentives for biodiversity conservation (Ansink and Bouma 2013; Zavalloni et al. 2019).

The aim of the paper is threefold. First, we seek to determine the size and the composition of the stable coalitions (SCs) within which farmers are willing to cooperate for the provision of pollination service, and to what extent these coalitions yield economic gains with respect to the NE. The second objective is to investigate the role of the landscape structure on the cooperation and conservation outcomes. The third objective is to assess how different public policies targeting habitat conservation affect coalition stability, and whether a policy design fostering cooperation among farmers would lead to budget-effectiveness improvements. We examine three different instruments that are often implemented in the USA and Europe: (i) individual homogeneous per-hectare payments; (ii) minimum participation rules (MPR), where a bonus is paid to each coalition member if the total habitat area exceeds a given threshold; and (iii) price premiums for fruits when pollinators are managed in common. We do not aim to find the optimal conservation policy but rather, more modestly, the budget-effectiviness of THE different instruments, highlighting some possible perverse results of existing policies when coalition formation is addressed. Our analysis is valuable for policymakers, in particular in Europe, where a large share of the Common Agricultural Policy (CAP) budget is allocated to agri-environmental schemes, and where efforts have been made to implement collective incentives (Franks 2019).

For these purposes, we formulate a spatially-explicit bioeconomic model of nine farmers growing annual crops and fruits that can dedicate a share of their arable lands to (semi-) natural habitats (e.g., set-aside areas, flower strips, hedgerows). Pollinator abundance increases the fruit yields but decreases with the distance to the habitats. We first analytically determine the conservation choices within the alternative coalitions and the impact of the considered policy instruments on these choices. However, the spatially-explicit nature of the problem prevents us from determining analytically the SCs; we thus numerically determine in a second step the SCs over randomly generated landscapes characterised by different degrees of spatial autocorrelation of fruit tree covers. We calibrate the model on fruit farms from Emilia-Romagna (Italy).

We contribute to the literature on cooperative management of ES in agricultural landscapes in several ways. First, we expand the knowledge on the benefits of cooperative management for productive ES by accounting for the stability of partial coalitions. For example, we find that the GC is never stable without policy intervention, but that some small coalitions of two or three farmers can be stable. Albeit small, the emergence of these coalitions entails average increases in total profits of $2.5 \%$ compared to the NE. Second, most of the existing literature has focused on the efficiency or budget-effectiveness of collective measures for the provision of unproductive public goods (Bouma et al. 2020; Dupraz et al. 2009). We here explore the effect of collective measures, and policy instruments in general, in the case of a public good that jointly provides non-use values (biodiversity conservation) and productive benefits (pollination), i.e. in case of within-group externalities (Kotchen and Segerson 2019). This issue has been so far investigated for fishery (Zhou and Segerson 2016) and pollution control (Willinger et al. 2014). On biodiversity conservation, few papers analyse these collective measures in this context other than in rather abstract ways (Ansink and Bouma 2013; Zavalloni et al. 2019). Here, we find that per-hectare payments or MPR schemes do not necessarily increase the habitat area when the targeted public good also generates within-group externalities. Indeed, these instruments can reduce the stability of coalitions that initially conserved more habitats: despite the new incentives, this effect can lead to fewer habitats at the margin. Moreover, the price premium may be a budgeteffective instrument to conserve habitats, but only when the spatial autocorrelation of fruit 
tree covers is low. Finally, very few papers from the coalition formation literature address a spatially-explicit distribution of benefits (Alvarado-Quesada and Weikard 2017; Costello et al. 2017; Gengenbach et al. 2010) or a high degree of heterogeneity (Bakalova and Eyckmans 2019). Contrary to the aforementioned papers, we move closer to reality by making endogenous to the model the individual decision on where to implement conservation efforts (Busby et al. 2012). We also generalize their approach to the case of the voluntary contribution to a public good with (i) heterogeneous agents, (ii) spatial interactions among agents and (iii) calibrated data.

The structure of the paper is as follows. Section 2 describes a general modelling framework to analyse (i) the coalition formation and corresponding land-use decisions and (ii) the impacts of the alternative policies on them. Section 3 presents the spatially-explicit bioeconomic model. The results are presented in Sect. 4. Section 5 discusses the results and provides concluding remarks.

\section{Theoretical analysis}

\subsection{Model description}

In this section, we theoretically describe the short-term maximization problem of farmers managing pollination service individually or collectively. Imagine a landscape shared by a population of farmers $\mathbf{I}=\{1, \ldots, I\}$. Without loss of generality, we assume that each farm has a single plot of one hectare with an exogenous share $f_{i}$ allocated to fruit production. ${ }^{2}$ The remaining available land for each farm $i$ is $\left(1-f_{i}\right)$ and can be devoted to annual crops or habitats $e_{i}$. The gross margin of arable crops $\Pi_{i}^{a}$ is a concave function of the area devoted to annual crops $\left(1-f_{i}-e_{i}\right)$ :

$$
\Pi_{i}^{a}=\pi^{a} \cdot\left(1-f_{i}-e_{i}\right)-\frac{1}{2} \cdot c \cdot\left(1-f_{i}-e_{i}\right)^{2},
$$

where $\pi^{a}=p^{a} \cdot y^{a}$ represents marginal revenues (price times yields) and $c$ is the cost parameter. ${ }^{3}$ Such a function is a standard specification in the agricultural economic literature as it easily describes decreasing return to areas for annual crops (e.g. Heckelei and Wolff 2003).

We consider that the fruit gross margin $\Pi_{i}^{f}$ on farm $i$ depends positively on the abundance of pollinators $\vartheta_{i}$ on $i$ :

$$
\Pi_{i}^{f}=f_{i} \cdot\left(p^{f} \cdot y^{f} \cdot\left(a+b \cdot \vartheta_{i}\right)-C^{f}\right),
$$

where $p^{f}$ is the fruit price, $y^{f}$ is the reference (exogenous) fruit yield and $C^{f}$ is the exogenous per-hectare cost for fruit production. ${ }^{4}$ The gross margin $\Pi_{i}^{f}$ depends on pollination as in Cong et al. (2014): $a$ and $b$ are parameters of the yield function such that $a+b=1$, where $a$ is the share of fruit yield that is independent of pollination and $b$ is the share that depends on the abundance of pollinators.

\footnotetext{
2 The assumption of exogeneous fruit area is likely to hold in the short-term.

3 For simplification, we assume that the prices and yields of arable crops are homogeneous among farms.

4 Fruit production is mostly intensive in labour and capital (Silva and Aragão, 2008), which are assumed to be exogenous in the short-term.
} 
The abundance of pollinators $\vartheta_{i}$ depends negatively on the distance to habitats. For a given farm $i$, the pollinators' abundance is:

$$
\vartheta_{i}=\sum_{k=1}^{I} e_{k} \cdot \alpha \cdot \exp ^{-\beta \cdot d_{i k}}
$$

where $\alpha$ is a scale parameter that describes the habitat suitability for the pollinators, $d_{i k}$ is the distance between two farms and $\beta$ is a distance parameter such that the pollinators' abundance in $i$ decreases with the distance between $i$ and the habitats in $k$. A similar ecological function has been used by Cong et al. (2014) building on Lonsdorf et al. (2009). Because the pollination service on each farm is affected by the area and location of habitats over the entire landscape, the ecological function creates an interdependency among all of the farms: the pollination service is a (local) public good.

The farm profit function $\Pi_{i}$ is defined by relations (1), (2) and (3) with $\Pi_{i}=\Pi_{i}^{a}+\Pi_{i}^{f}$. The chosen functional forms imply that the benefits from pollination enter linearly into the profit function, i.e. that pollination presents constant productivity. This is a familiar assumption in the literature on public goods, which notably implies orthogonal reaction functions in conservation choices among farms. In other words, the contribution to public goods by one farm does not affect the contributions of the others (Carraro and Siniscalco 1993)..$^{5}$

The existing literature on the cooperative management of productive ES only compares the NE with the GC outcomes (e.g., Cong et al. 2014). We present these two situations. In the NE, each farmer decides on the habitat area, taking into account only her own payoffs and taking others' decisions as given. Each farm $i$ faces the following maximization problem:

$$
\max _{e_{i}} \Pi_{i}=\pi^{a} \cdot\left(1-f_{i}-e_{i}\right)-\frac{1}{2} \cdot c \cdot\left(1-f_{i}-e_{i}\right)^{2}+f_{i} \cdot\left(p^{f} \cdot y^{f} \cdot\left(a+b \cdot\left(e_{i} \cdot \alpha+\sum_{\substack{k=1 \\ k \neq i}}^{I} e_{k} \cdot \alpha \cdot \exp ^{-\beta \cdot d_{i k}}\right)\right)-C^{f}\right),
$$

where the conservation efforts of the farmers other than $i$ are considered fixed. Such an equilibrium is determined by computing the first-order conditions (FOC) of equation (4) with respect to $e_{i}$ :

$$
\frac{\partial \Pi_{i}}{\partial e_{i}}=0=-\pi^{a}+c \cdot\left(1-f_{i}-e_{i}\right)+f_{i} \cdot Y^{f} \cdot \alpha,
$$

where $Y^{f}=p^{f} \cdot y^{f} \cdot b$ is the marginal revenues per hectare induced by one pollinator. The difference $\pi^{a}-c \cdot\left(1-f_{i}-e_{i}\right)$ is the increasing marginal opportunity cost of providing habitat on farm $i$. The opportunity cost depends positively on the fixed fruit area $f_{i}$ and is heterogeneous across farms. The term $f_{i} \cdot Y^{f} \cdot \alpha$ represents farm $i$ 's marginal benefits of providing habitats through its indirect effect on pollination, ignoring the productive externalities generated to other farms. The optimal habitat area for farm $i$ under the NE $e_{i}^{N}$ is obtained when these benefits equal the opportunity cost, leading to:

\footnotetext{
5 A game characterised by non-orthognal reaction functions and heterogenous players game has been numericaly assessed by e.g. Osmani and Tol (2010). However, they only consider two-players types. In our case, the spatial characteristics of the game makes the population of players fully heterogenous. Thus, we choose orthogonal reaction functions to simplify the game structure and focus on the spatial issues.
} 


$$
e_{i}^{N}= \begin{cases}0 & \text { if } \pi^{a}>f_{i} \cdot Y^{f} \cdot \alpha+c \cdot\left(1-f_{i}\right) \\ \frac{f_{i} \cdot Y^{f} \cdot \alpha-\pi^{a}}{c}+\left(1-f_{i}\right) & \text { if } f_{i} \cdot Y^{f} \cdot \alpha<\pi^{a} \leq f_{i} \cdot Y^{f} \cdot \alpha+c \cdot\left(1-f_{i}\right) \\ 1-f_{i} & \text { if } \pi^{a} \leq f_{i} \cdot Y^{f} \cdot \alpha\end{cases}
$$

A positive solution is obtained when the marginal benefits of habitat are greater than the marginal profits of arable lands (in case the area is allocated to arable lands). The entire plot is allocated to habitat when the marginal benefits of habitat are higher than the marginal revenues of arable lands. In other cases, an interior solution is obtained. Equation (6) shows that the interior solution $e_{i}^{N}$ decreases with the gross margin of annual crops but increases with (i) the reference fruit yield, (ii) the fruit price, (iii) the share of the fruit yield that depends on pollination, and (iv) the habitat suitability for pollinators. The influence of the cost parameter and the fruit area on $e_{i}^{N}$ are more complex and depend on their relative values compared to the other parameters.

The optimal landscape in terms of habitat (holding fixed the fruit area) is obtained when the sum of the individual profits is maximized. This case is obtained when farms cooperate all together within the GC. The optimal habitat areas in such a case are obtained by maximizing:

$$
\max _{e} \sum_{i=1}^{I} \Pi_{i}=\sum_{i=1}^{I}\left[\pi^{a} \cdot\left(1-f_{i}-e_{i}\right)-\frac{1}{2} \cdot c \cdot\left(1-f_{i}-e_{i}\right)^{2}\right]+\sum_{i=1}^{I} f_{i} \cdot\left[p^{f} \cdot y^{f} \cdot\left(a+b \cdot \sum_{k=1}^{I} e_{k} \cdot \alpha \cdot \exp ^{-\beta \cdot d_{i k}}\right)-C^{f}\right],
$$

where $\mathbf{e}$ is the vector of habitat area for the $I$ farms. The FOC of (7) on $e_{i}$ leads to:

$$
-\pi^{a}+c \cdot\left(1-f_{i}-e_{i}\right)+\sum_{k=1}^{I} f_{k} \cdot Y^{f} \cdot \alpha \cdot \exp ^{-\beta \cdot d_{i k}}=0 .
$$

The opportunity cost of providing $e_{i}$ is thus similar to the NE case (equal to $\pi^{a}-c \cdot\left(1-f_{i}-e_{i}\right)$ ). However, the benefits are larger (equal to $\sum_{k=1}^{I} f_{k} \cdot Y^{f} \cdot \alpha \cdot \exp ^{-\beta \cdot d_{i k}}$ ) as farmers internalize the effects of their individual land-use decisions on the others' profits. The optimal habitat area is then:

$$
e_{i}^{*}= \begin{cases}0 & \text { if } \pi^{a}>\sum_{k=1}^{I} f_{k} \cdot Y^{f} \cdot \alpha \cdot \exp ^{-\beta \cdot d_{i k}}+c\left(1-f_{i}\right) \\ \frac{\sum_{k=1}^{I} f_{k} \cdot Y \cdot \cdot \cdot \cdot \exp ^{-\beta \cdot d d_{k}-\pi^{a}}}{c}+\left(1-f_{i}\right) & \text { if } \sum_{k=1}^{I} f_{k} \cdot Y^{f} \cdot \alpha \cdot \exp ^{-\beta \cdot d_{i k}}<\pi^{a} \leq \sum_{k=1}^{I} f_{k} \cdot Y^{f} \cdot \alpha \cdot \exp ^{-\beta \cdot d_{i k}}+c\left(1-f_{i}\right) \\ 1-f & \text { if } \pi^{a} \leq \sum_{k=1}^{I} f_{k} \cdot Y^{f} \cdot \alpha \cdot \exp ^{-\beta \cdot d_{i k}}\end{cases}
$$

Similarly to the NE, the solution of the optimal lanscape is bounded by the plot area in case the aggregate marginal benefit of habitat are greater then the marginal revenes of arable land. Comparing the interior solutions in (6) to (8), we easily find that the GC leads to higher levels of habitats than the NE.

\subsection{The formation of coalitions for pollination management}

We now turn to the case in which a group of farms collectively manage the pollination service. There are formally $2^{I}-I$ non trivial coalitions plus the NE for the population $\mathbf{I}$. To assess which of the coalitions are stable, we apply a two-stage game described by Barrett 
(1994). The first stage is the coalition formation stage: farmers, anticipating the land allocation decisions taken in the second stage, choose to become a member of the coalition or not. The coalitions that could emerge are the ones that are both internally and externally stable. Internal stability implies that no coalition member has incentives to defect (the members' profits are higher inside the coalition than outside). The external stability condition postulates that non-members prefer to remain outside the coalitions (the nonmembers' profits are higher outside the coalition). In the second stage, farmers decide on the lands allocated to habitat; this decision depends on whether the farm is a member of the coalition or not. The usual assumption is that coalition members decide on the public good contribution (the habitats) taking into account the aggregate profit accruing to the coalition. In contrast, non-members maximize their own individual profit. This coalitional equilibrium, where the coalition members maximize the joint profit taking as given the non-members' choices, is called "partial agreement Nash equilibrium" (Chander and Tulkens 1997). In the following, we solve the game using backward induction, starting from the second stage.

Call $\mathbf{S}$ the vector indicating the composition of a given coalition within the set of the $2^{I}-I+1$ possible coalitions. For example, $\mathbf{S}=(1,1,0, \ldots, 0)$ is the coalition of farms 1 and 2 . The superscripts $s$ and $n s$, respectively, indicate whether farm $i$ is part of coalition $\mathbf{S}$ or not. Assume that farm $i$ belongs to the coalition $\mathbf{S}$. In the second stage, any farm $i \in \mathbf{S}$ chooses the habitat areas by maximizing the aggregated profit of the coalition members:

$$
\max _{e^{s}} \sum_{i \in S} \Pi_{i}^{s}(S)=\sum_{i \in S}\left[\pi^{a} \cdot\left(1-f_{i}-e_{i}\right)-\frac{1}{2} \cdot c \cdot\left(1-f_{i}-e_{i}\right)^{2}\right]+\sum_{i \in S} f_{i} \cdot\left[p^{f} \cdot y^{f} \cdot\left(a+b \cdot \sum_{k=1}^{I} e_{k} \cdot \alpha \cdot \exp ^{-\beta \cdot d_{i k}}\right)-C^{f}\right],
$$

where $\mathbf{e}^{S}$ is the vector of the habitat areas for the farms within $\mathbf{S}$. The FOC of (9) on $e_{i}$ leads to:

$$
e_{i}^{s}= \begin{cases}0 & \text { if } \pi^{a}>\sum_{k \in S} f_{k} \cdot Y^{f} \cdot \alpha \cdot \exp ^{-\beta \cdot d_{i k}}+c \cdot\left(1-f_{i}\right) \\ \frac{\sum_{k \in S} f_{k} \cdot Y^{f} \cdot \alpha \cdot \cdot \exp ^{-\beta \cdot d_{i k}}-\pi^{a}}{c}+\left(1-f_{i}\right) & \text { if } \sum_{k \in S} f_{k} \cdot Y^{f} \cdot \alpha \cdot \exp ^{-\beta \cdot d_{i k}}<\pi^{a} \leq \sum_{k \in S} f_{k} \cdot Y^{f} \cdot \alpha \cdot \exp ^{-\beta \cdot d_{i k}}+c \cdot\left(1-f_{i}\right) . \\ 1-f & \text { if } \pi^{a} \leq \sum_{k \in S} f_{k} \cdot Y^{f} \cdot \alpha \cdot \exp ^{-\beta \cdot d_{i k}}\end{cases}
$$

Relation (10) states that the farms within $\mathbf{S}$ internalise the externalities they generate to other coalition members. ${ }^{6}$ By contrast, the non-members only internalise their own profits and behave as in Eq. (6). It is worth noting that such a spatially-explicit pollination game is a positive externality game (Bayramoglu et al. 2018), which implies that the incentives for non-members to join the coaliton decrease as the size of the coalition increases (see Appendix 1).

In the first stage, the coalition is formed. The stability conditions are formally described by:

$$
\Pi_{i}^{s}(S) \geq \Pi_{i}^{n s}(S \backslash\{i\}),
$$

and

\footnotetext{
${ }^{6}$ Note that $\mathbf{S}=(1, \ldots, 1)$ leads to the GC outcomes where the landscape is described by Eq. (8). Similarly, if the coalition is of size one, relation (10) is identical to (6) and describes the NE.
} 


$$
\Pi_{i}^{n s}(S) \geq \Pi_{i}^{s}(S \cup\{i\}) .
$$

The coalitions that spontaneously arise are the ones that respect both the conditions of internal stability (relation (11)) and of external stability (relation (12)). For coalition $\mathbf{S}$ to be stable, the stability conditions imply that all the members of the coalitions have incentives to remain within $\mathbf{S}$ (relation (11)), while all of the non-members have incentives to remain outside $\mathbf{S}$ (relation (12)). We assume that there can be only a single coalition within the landscape such that farmers who are not part of $\mathbf{S}$ constitute singletons. ${ }^{7}$

With heterogenous farmers, the analytical assessment of the stability of the coalitions - described by relations (11) and (12) - is only possible with strong assumptions and/or with high simplifications. With few exceptions (Finus and McGinty, 2019; Weikard et al. 2015), most of the papers deal with the problem by solving it numerically (Botteon and Carraro 1997; Sáiz et al. 2006; Vogt 2016). We embrace this approach (see Sects. 3 and 4).

\subsection{Agri-Environmental Policies}

The previous results present the endogenous coalition formation in a no-policy context. Farmers have incentives to cooperate to maintain habitats due to THE pollination service but, since they do not internalise the external value of conserving habitats (e.g. non-use values of pollinators; Hanley et al. 2015), they will underprovide them. In this context, the policymakers could provide additional incentives to conserve habitats. The introduction of policy instruments that incentivize habitat conservation should affect the farmers' land-use decisions and, ultimately, may influence the farmers' cooperation decisions. We present the impacts of three policy instruments on the cooperation outcomes in the following.

\subsubsection{Per-Hectare Payments}

The regulator offers, for any farm $i$, a per-hectare payment $q^{e}$ for each hectare devoted to habitats $e_{i}$, irrespective of whether farms cooperate or not. In this case, the optimal area devoted to habitats by the farmers in $\mathbf{S}$ - including the singletons, the GC and all of the intermediate coalitions - is obtained by maximizing the aggregated profit of the coalition members:

$$
\begin{aligned}
\max _{e^{s}} \sum_{i \in S} \Pi_{i}^{S}(S)= & \sum_{i \in S}\left[\pi^{a} \cdot\left(1-f_{i}-e_{i}\right)-\frac{1}{2} \cdot c \cdot\left(1-f_{i}-e_{i}\right)^{2}+q^{e} \cdot e_{i}\right] \\
& +\sum_{i \in S} f_{i} \cdot\left[p^{f} \cdot y^{f} \cdot\left(a+b \cdot \sum_{k=1}^{I} e_{k} \cdot \alpha \cdot \exp ^{-\beta \cdot d_{i k}}\right)-C^{f}\right],
\end{aligned}
$$

Relation (13) is identical to relation (9) except that it also includes the per-hectare payments of the coalition members. The FOC of $e_{i}$ for Eq. (13) leads to:

\footnotetext{
7 This is an usual assumption in the literature on coalition formation. Although this assumption could be relaxed, it would result in a dramatic increase in the possible number of partitions (i.e. the sets of coalitions composed of independent farmers).
} 


$$
e_{i}^{s}= \begin{cases}0 & \text { if } \pi^{a}>\sum_{k \in S} f_{k} \cdot Y^{f} \cdot \alpha \cdot \exp ^{-\beta \cdot d d_{k}}+q^{e}+c \cdot\left(1-f_{i}\right) \\ \frac{\sum_{k \in S} f_{k} \cdot Y^{f} \cdot \alpha \cdot \cdot \exp -\beta \cdot d_{k}+q^{e}-\pi^{a}}{c}+\left(1-f_{i}\right) & \text { if } \sum_{k \in S} f_{k} \cdot Y^{f} \cdot \alpha \cdot \exp ^{-\beta \cdot d_{k}}+q^{e}<\pi^{a} \leq \sum_{k \in S} f_{k} \cdot Y^{f} \cdot \alpha \cdot \exp ^{-\beta \cdot \cdot d_{k}}+q^{e}+c \cdot\left(1-f_{i}\right) \\ 1-f & \text { if } \pi^{a} \leq \sum_{k \in S} f_{k} \cdot Y^{f} \cdot \alpha \cdot \exp ^{-\beta \cdot d_{k}}+q^{e}\end{cases}
$$

As in Eq. (10), the farms within the coalition integrate the externalities they generate to other members. However, the farms allocate more habitats in (14) than in (10) due to the additional payment $q^{e}$. We call this additional habitat allocation within each coalition the effect at the intensive margin. The intensive margin effect, however, also affects the stability conditions (11) and (12). Indeed, the modifications of the conserved habitats from (10) to (14) modify the profits within the different coalitions such that one coalition that was stable without the perhectare payments may no longer be stable with the payment, or the other way around. We refer to this effect on the stability of the coalitions as the effect at the extensive margin. Whereas the effect at the intensive margin of the per-hectare payment leads necessarily to more habitats, the effect at the extensive margin may result in more or less habitats, depending on if the payment fosters or reduces the incentives for cooperation. The total effect of the per-hectare payment may thus be positive or negative depending on whether the effects at the extensive margin offsets or not the effects at the intensive margin. The extensive margin effect is not usually considered in the literature on agri-environmental payments as most of the literature deems that farmers have no incentive to conserve habitats - individually or in common - in the absence of payments.

\subsubsection{Minimum Participation Rule on Natural Habitat Areas}

The regulator offers, for any farm $i$ within $\mathbf{S}$, a lump-sum payment $Q^{M P R}$ if the total lands devoted for habitats by $\mathbf{S}$ is higher than a threshold $\bar{e}$. This threshold corresponds to a share of the total arable lands within the landscape. The farms outside $\mathbf{S}$ do not receive any payment. The lump-sum payment is paid, individually, to all of the farmers in coalition $\mathbf{S}$ if $\bar{e}$ is reached, independently of their individual conservation efforts. Such a scheme has been documented by Dupraz et al. (2009) in a French case. In such a setting, the optimal habitat area in any of the coalitions is obtained by maximizing:

$$
\max _{e^{S}} \sum_{i \in S} \Pi_{i}^{S}=\left\{\begin{array}{l}
\sum_{i \in S}\left[\pi^{a} \cdot\left(1-f_{i}-e_{i}\right)-\frac{1}{2} \cdot c \cdot\left(1-f_{i}-e_{i}\right)^{2}+Q^{M P R}\right]+ \\
\sum_{i \in S} f_{i} \cdot\left[p_{i}^{f} \cdot y^{f} \cdot\left(a+b \cdot \sum_{k=1}^{I} e_{k} \cdot \alpha \cdot \exp ^{-\beta \cdot d_{i k}}\right)-C^{f}\right] \text { if } \sum_{i \in S} e_{i} \geq \bar{e} \\
\sum_{i \in S}\left[\pi^{a} \cdot\left(1-f_{i}-e_{i}\right)-\frac{1}{2} \cdot c \cdot\left(1-f_{i}-e_{i}\right)^{2}\right]+ \\
\sum_{i \in S} f_{i} \cdot\left[p_{i}^{f} \cdot y^{f} \cdot\left(a+b \cdot \sum_{k=1}^{I} e_{k} \cdot \alpha \cdot \exp ^{-\beta \cdot d_{i k}}\right)-C^{f}\right] \text { if } \sum_{i \in S} e_{i}<\bar{e}
\end{array}\right.
$$

The MPR introduces a kink in the profit function of the coalition members. The solution of (15) in terms of land allocation is either the same as equation (10), or exactly $\sum_{i \in S} e_{i}^{s}=\bar{e}$. Indeed if the MPR is lower than the sum of the solutions of (10), i.e. if $\bar{e} \leq \sum_{i \in S} e_{i}^{s}$, the lump-sum payment is granted at no effort for the coalition members. On 
the contrary, if $\bar{e}>\sum_{i \in S} e_{i}^{s}$, then coalition members will compare the aggregate profits at $\sum_{i \in S} e_{i}^{s}$ and at $\bar{e}$ and will choose to enroll an aggregate level of habitat equal to $\bar{e}$ only if the lump-sum payments are high enough to cover the additional costs of selecting a habitat size greater than the optimal one in equation (10). Moreover, as is the case for the homogenous per-hectare payment, the MPR can either increase or decrease the conservation efforts, depending on its effects on the stability of the alternative coalitions. This effet can occur even if the threshold is lower than the solution of (15) due to the effects on alternative coalitions.

\subsubsection{Price Premium}

The regulator offers, for any farm $i$ in $\mathbf{S}$, a homogeneous price premium $\rho$ for fruit production. The farms outside $\mathbf{S}$ do not receive the price premium. This instrument corresponds to a particular type of label where the required practice is the cooperative management of the pollinators. ${ }^{8}$ In this setting, the optimal area devoted to habitats in $\mathbf{S}$ is obtained by maximizing:

$$
\begin{aligned}
\max _{e^{S}} \sum_{i \in S} \Pi_{i}^{S}(S)= & \sum_{i \in S}\left[\pi^{a} \cdot\left(1-f_{i}-e_{i}\right)-\frac{1}{2} \cdot c \cdot\left(1-f_{i}-e_{i}\right)^{2}\right] \\
& +\sum_{i \in S} f_{i} \cdot\left[p^{f} \cdot(1+\rho) \cdot y^{f} \cdot\left(a+b \cdot \sum_{k=1}^{I} e_{k} \cdot \alpha \cdot \exp ^{-\beta \cdot d_{i k}}\right)-C^{f}\right]
\end{aligned}
$$

The FOC of $e_{i}$ for Eq. (16) leads to:

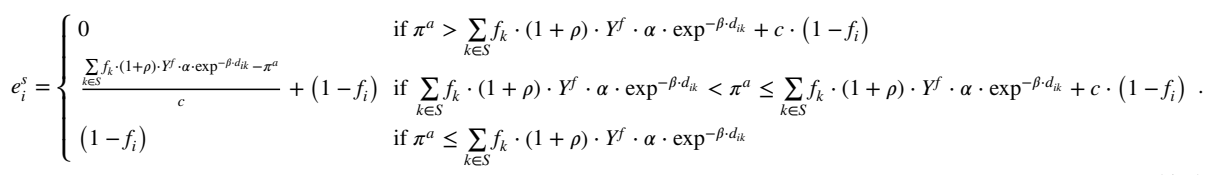

As in (14), the coalitions conserve more habitats in (17) than in the absence of external incentives (as in equation (10)). The price premium thus presents a positive intensive margin effect. The modifications of the optimal habitat areas from (10) to (17) also change the profits of the different coalitions that ultimately affect their stability (at least the external stability). There is therefore also an extensive margin effect from the price premium. The total effect of the price premium is ambiguous and depends on whether or not the extensive margin effects offset the positive effects at the intensive margin. We investigate numerically the effects of these instruments in the following simulations.

\footnotetext{
${ }^{8}$ This kind of price premium has been examined by Punt and Wesseler (2018) with regard to the formation of clubs, the members of which do not produce genetically modified crops.
} 
Fig. 1 Location and structure of the farms and average fruit area per plot

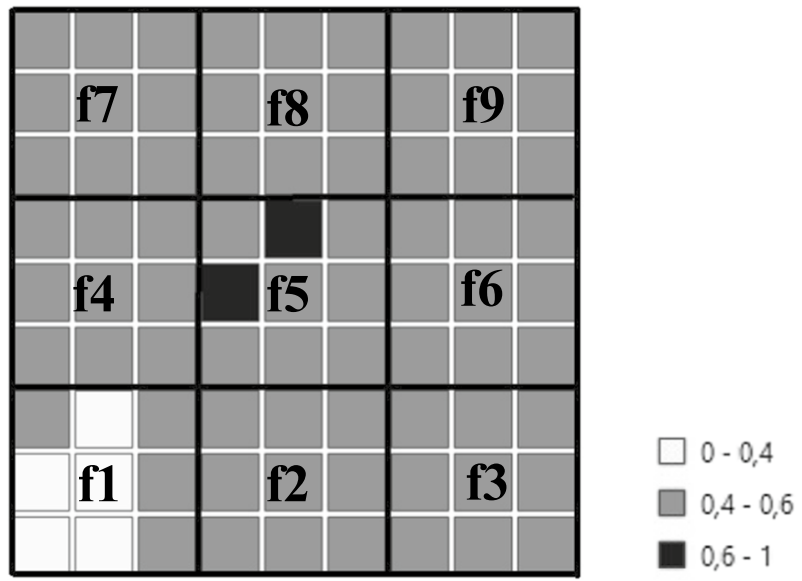

\section{Numerical Simulations}

The theoretical analysis suggests that partial cooperation for pollination service is possible in agricultural landscapes and that various policy instruments may foster or decrease interest therein. The analytical solutions are, however, impossible to obtain given the considerations of the farms' heterogeneity and the spatially-explicit nature of pollination. We thus illustrate our theoretical analysis by formulating a numerical spatially-explicit bioeconomic model. We simulate the coalition formation process using theoretical landscapes shared by nine fruit farms. Contrary to the theoretical model, we consider that each farm owns nine plots of one hectare each. The increase in the number of plots per farm from one to nine provides a more realistic setting and makes it possible to deepen the investgations on the effects of the landscape structure. There are thus $9 \times 9=81$ plots within the simulated landscapes and $2^{9}-9+1=504$ possible coalition structures, i.e. partition of farmers when there is only one non-trivial coalition.

Agricultural landscapes present a positive spatial autocorrelation among the covers: neighbouring plots are more likely to present similar covers as they share similar pedoclimatic conditions (Pasher et al. 2013). We generate 81 random landscapes such that the Moran's I statistics on the fruit areas take successively the value of 0 (totally random landscape) to 0.8 (very high spatial autocorrelation), with a step of $0.01 .^{9}$ To generate comparable landscapes, we always attribute a fruit share of 0.01 for the bottom left plot and set the average fruit area at the landscape scale at 0.5. We did not generate Moran's I values higher than 0.8 as real landscapes do not seem to exceed such a threshold (Pasher et al. 2013). As in the theoretical part, the remaining arable areas can either be allocated to habitats or to annual crops. ${ }^{10}$ Figure 1 presents the farm localization and the average plot composition of the 81 generated landscapes. Figure 1 highlights a spatial clustering where farm f1 presents the lowest amount

\footnotetext{
9 The Moran's I is defined (using the notation employed in our model) as: $I=\frac{N}{W} \frac{\sum_{i} \sum_{j} w_{i j}\left(f_{i}-\bar{f}\right)\left(f_{j}-\bar{f}\right)}{\sum_{i}\left(f_{i}-\bar{f}\right)^{2}}$, with $W=\sum_{i} \sum_{j} w_{i j}, N$ indicates the number of plots and $\bar{f}$ is the average fruit cover (Moran, 1948). We used the rook matrix to set the weights. In such a case, $w_{i j}=1$ only if $i$ and $j$ share a common segment - i.e. only if they share either the north, south, east or west borders - and $w_{i j}=0$ otherwise.

10 Note that if we generate the landscapes on the spatial autocorroleation of fruit areas, it also clustered the average profitability of annual crop production (see relation (1)).
} 
of fruit areas and where f5 has, on average, the highest amount of fruits. Figure 7 in appendices displays the average landscape structure for the different Moran's I quartiles: it shows that the landscapes are more and more clustered as the Moran's I increases.

In the benchmark setting (without any policy instrument), we first set $\alpha=\beta=0.2$. This parametrization ensures that each farm generates externalities to all of the other farms. For example, the centroid of farm $\mathrm{f} 1$ is located $0.85 \mathrm{~km}$ from the centroid of farm $\mathrm{f} 9$ (located at the other extremity of the landscape - Fig. 1) and, in the case where all farms devoted the same amount of habitats, about $15 \%$ of the pollination service on $\mathrm{f} 1$ depends on farm f1's own choices, while about 9\% depends on farm f9's choices. This figure seems coherent with the observed dispersion of pollinators, which can pollinate up to $1.5 \mathrm{kms}$ from their habitats (Zurbuchen et al. 2010). We present the results using this parametrization in Sect. 4.1. Section 4.2. is a sensitivity analysis with alternative parametrization, formally with $\alpha \in\{0.1,0.2,0.3\}$ and $\beta \in\{0.1,0.2,0.3\}$. According to Eq. (3), an increase in $\beta$ reduces the pollinators' dispersion and the corresponding externalities among farms. On the contrary, an increase in $\alpha$ increases the pollinators' density and the externalities among farms. Accordingly, a change in the levels of these parameters may modify our results. Moreover, we fix $b=0.1$ such that between 5 to $30 \%$ of the fruit yields depend on pollination, depending on the levels of $\alpha$ and $\beta$ (about $10 \%$ in the case of the benchmark). An increase in $b$ would thus not be coherent with the observed level of pollination worldwide (Gallai et al. 2009; Therond et al. 2017). In addition, Cong et al. (2014) showed that their main conclusion was insensitive to the levels of $b$ : all farmers would gain to act cooperatively regardless of $b$. Finally, we calibrate the profitability of annual crops and fruits using the Farm Accountancy Data Network for Emilia-Romagna in 2017. ${ }^{11}$ We simulate the effects of the policy instruments using the parametrization of the benchmark in Sect. 4.3.

\section{Results}

\subsection{The Benchmark}

Table 1 displays the average outcomes for the 81 simulated landscapes, in term of invidivual profits (for the NE, the GC and for the members of the SC with at least two members) and cooperation outcomes. As expected, the NE is characterised by the lowest individual profits. The GC provides the highest individual profits, which are on average $13.8 \%$ higher compared to the NE. However, the GC is not stable and hence cannot spontaneously appear. Indeed, there are on average 4.14 SCs per landscape (among the 504 possible ones), and all of them are composed of two farms. The cooperation among farms for the management of pollination is thus limited. Partial cooperation increases on average the aggregate profits by $2.5 \%$ compared to the NE but are still $9.9 \%$ lower than the GC (see "Total landscape" in Table 1). For the coalition members, however, the individual profits are on average $13.1 \%$ higher in the SC than in the NE and only $0.7 \%$ lower than in the GC (see "Farm average" in Table 1). ${ }^{12}$

\footnotetext{
${ }^{11}$ Formally, we used $\pi^{\mathrm{a}}=800 € / \mathrm{ha}, c=88, \pi^{\mathrm{f}}=8610 € / \mathrm{ha}$ and $C^{f}=0 € / \mathrm{ha}$. We calibrated the cost parameter $c$ such that the average observed wheat gross margins in Emilia-Romagna equal the average gross margins in our theoretical landscapes.

${ }^{12}$ Interestingly, the average individual profits for coalition members can be higher within the SC than within the GC, e.g. for (corner) farms $\mathrm{f} 1, \mathrm{f} 3$ and $\mathrm{f} 7$. This reason illustrates the unstability of the GC in our settings.
} 
Table 1 Average profits in the NE, GC and SCs and features of the SCs $(\mathrm{N}=81)$

\begin{tabular}{lccccc}
\hline & Profit NE $(€)$ & Profit GC $(€)$ & Profit SC $(€)$ & Number SC & Size SC \\
\hline f1 & 30,863 & 33,793 & 44,958 & 0.17 & 2.00 \\
f2 & $(11,009)$ & $(13,581)$ & $(4,763)$ & $(0.70)$ & $(0.00)$ \\
& 40,149 & 45,893 & 49,359 & 0.73 & 2.02 \\
f3 & $(11,521)$ & $(14,340)$ & $(5,121)$ & $(1.37)$ & $(0.13)$ \\
& 41,333 & 46,383 & 46,424 & 0.90 & 2.00 \\
f4 & $(9,075)$ & $(11,117)$ & $(3,711)$ & $(1.34)$ & $(0.00)$ \\
& 42,041 & 48,292 & 47,617 & 0.75 & 2.02 \\
f5 & $(10,395)$ & $(13,025)$ & $(5,432)$ & $(1.37)$ & $(0.00)$ \\
& 48,814 & 57,594 & 50,244 & 1.41 & 2.00 \\
f6 & $(11,131)$ & $(14,205)$ & $(5,463)$ & $(2.05)$ & $(0.00)$ \\
& 47,032 & 54,054 & 49,003 & 1.43 & 2.00 \\
f7 & $(11,042)$ & $(13,714)$ & $(5,225)$ & $(1.79)$ & $(0.00)$ \\
& 42,472 & 47,724 & 47,802 & 0.81 & 2.02 \\
f8 & $(11,035)$ & $(13,492)$ & $(6,111)$ & $(1.24)$ & $(0.00)$ \\
& 44,532 & 50,856 & 47,921 & 1.11 & 2.00 \\
f9 & $(10,455)$ & $(12,833)$ & $(5,089)$ & $(1.70)$ & $(0.00)$ \\
& 44,186 & 49,511 & 47,870 & 0.96 & 2.00 \\
Farm average & $(10,327)$ & $(12,430)$ & $(5,407)$ & $(1.34)$ & $(0.00)$ \\
& 42,380 & 48,233 & 47,911 & 0.92 & 2.01 \\
Total landscape & $(5,121)$ & $(6,593)$ & $(1,572)$ & $(1.08)$ & $(0.01)$ \\
& 381,424 & 434,099 & 390,987 & 4.14 & 2.00 \\
& $(2,423)$ & $(1,145)$ & $(2,620)$ & $(5.00)$ & $(0.00)$ \\
\hline
\end{tabular}

The results are computed based on the average of the 81 randomly simulated landscapes. The standard deviations are within brackets. "Number SC" indicates how many non-trivial SCs, per simulated landscape, each farmers is member of (or the average number of possible SCs for the line "total landscape"). "Size $\mathrm{SC}$ " indicates the average size of the SCs in which each farmer is member. The line "farm average" presents the average figures of the nine farms for all characteristics; in particular, the average profit in the SC is computed on the coalition members. The line "total landscape" presents the sum over the nine farmers; in particular, "Profit SC" includes the profits of the members and the non-members. The used pollination parameters are $\alpha=\beta=0.2$. There is no policy in the benchmark

The farm's fruit area and location affect its probability of choosing to become a coalition member. Indeed, the central farm (f5) is the most frequent member of the SCs (with its neighbour f6) and the one that benefits the most from cooperation (Table 1). The corner farms (except farm f9) are the least frequent members of the SCs. In particular, farm f1, for which the fruit area is the lowest, is the farm that cooperates the least. Its neigbours, $\mathrm{f} 2$ and $\mathrm{f} 4$, also cooperate significantly less than their symmetric equivalents $\mathrm{f} 6$ and $\mathrm{f} 8$, which is proably due to the lowest amount of fruit areas at there disposal (see Figure 7 in Appendix). Similarly, farm f9 cooperates more than farms $\mathrm{f} 2$ and $\mathrm{f} 4$ despite its corner position, likely because it has more fruit areas.

Figure 2 presents the share of arable land allocated to habitats for each plot in the different situations. In line with Table 1 , the NE is characterised by the lowest habitat area (57.68\%), whereas the GC would allocate all arable lands to habitats. The landscapes with at least one SC lead to higher habitat areas than the NE (65.06\% on average). Figure 2 shows that while the central farm tends to free-ride in the NE by benefiting from 


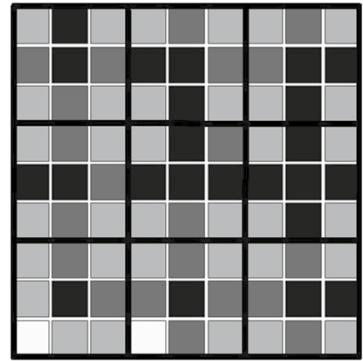

(a)

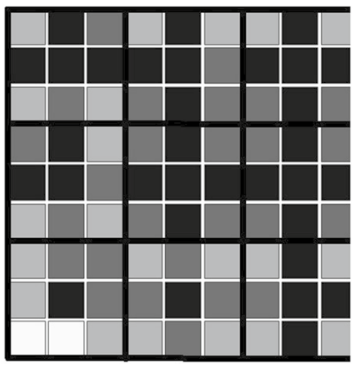

(b)

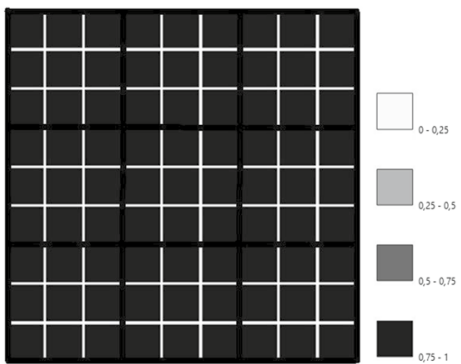

(c)

Fig. 2 Average habitats as shares of arable land over the 81 simulations for a the NE, b, the SC and $\mathbf{c}$ the $\mathrm{GC}$

neighbouring farms' choices, it is the one that allocates the highest share of land to habitats within the SCs. The corner farms (except farm f9) are the ones that put the least number of habitats within the SCs. In particular, f1 puts the least effort in the coalition as it is the farm with the least fruit area and thus with the least potential gains from cooperation.

We further deepen the relationships between cooperation and the landscape structure in Fig. 3. First, the number of SCs clearly decreases as the fruit areas are more spatially clustered (Fig. 3a). While there are up to $17 \mathrm{SCs}$ for landscapes with low spatial autocorrelation (with a Moran's I lower than 0.2), there are almost no SC for landscapes with high spatial autocorrelation. Indeed as fruits are more and more clustered, the number of farms that benefit the most from cooperation reduces, which decreases the number of SCs. Second, it seems that there is no clear relationship between coalition size and landscape structure: the SCs are of size two, whatever the level of spatial autocorrelation (Fig. 3b). This result is similar to Alvarado-Quesada and Weikard (2017) who find that 2-player coalitions are the only stable ones under a wide range of parameter levels. Third, $64 \%$ of these SCs are composed of neighbouring farms (Fig. 3c). This feature is highly variable among the landscapes but does not depend on the landscape structure, except to the extent that the variance increases with spatial autocorrelation. Fourth, the ratio of the aggregated profit of the GC over the aggregated profit in the NE varies between 1.127 and 1.160 (Fig. 3d) but does not seem to depend on the spatial structure. ${ }^{13}$ On the contrary, there is a negative relationship between, on one hand, the spatial autocorrelation of fruit tree covers and, on the other hand, the ratio of the aggregated profits within landscapes with a SC over those in the NE (Fig. 3d). Not only the probability to cooperate decreases with the spatial autocorrelation of fruit tree covers but the benefits within the SC decreases too. Fifth, the members of the SCs have significantly more fruits than the non-members (Fig. 3e). ${ }^{14}$ This is coherent with the literature on coalition formation: the players with the highest gains from cooperation (farms with the largest fruit areas, hence those that have greatest to gain from an increased pollination service) are the ones who are the most willing to cooperate, on average. Interestingly, coalition members are characterised by higher shares of fruits as the spatial autocorrelation increases. This feature may have the same cause than the decreasing number of SCs as the spatial autocorrelation increases: a landscape with high spatial

\footnotetext{
13 This ratio is often used as an indicator to determine the potential benefits of cooperation (Finus and McGinty, 2019).

${ }^{14}$ On average, the members have $57.14 \%$ of their lands for fruits while $47.95 \%$ of the non-members' lands are for fruits.
} 
autocorrelation is characterised by farms with very different levels of fruit and arable areas, which complexifies the possibility to find a mutually beneficial agreement among farms. Finally, the members of the SCs devote all of their arable lands to habitats while habitats occupy $54.92 \%$ of the non-members' arable lands (Fig. 3f), i.e. a bit less than in the NE (Fig. 2). Overall, greater benefits from cooperation entail greater contributions to habitats from the coalition members but, hence, higher positive spillovers that incentivizes farmers to free-ride. This mechanism is behind the "paradox of cooperation" (Barrett 1994), which describes how great potential gains from cooperation actually limit the size of the SCs.

\subsection{Sensitivity Analysis on Pollinator Abundance}

To check the robustness of our results, we solve the model using alternative values for $\alpha$ and $\beta$. Table 2 displays the cooperation outcomes for the alternative parametrizations. The sensitivity analysis confirms that there are few SCs per landscape, on average, and that the GC is never stable. The SCs are small (about two or three members - see Fig. 8 in Appendix 3 ) and mostly composed of neighbouring farms. In other words, an increase in $\beta$ tends to increase the SC size, while an increase in $\alpha$ decreases the SC size: in both cases, an increase in the pollinator density decreases the SC size.

The number of SCs is not related to $\beta$ and evolves non-linearly with $\alpha$. Its maximum is reached for $\alpha=0.2$ (see Fig. 9 in Appendix). This may illustrate that farmers have few incentives to cooperate both for low levels of $\alpha$ (due to the low pollinator density) and for high ones (high incentives to free-ride). In particular, setting $\alpha=0.3$ does not allow for the emergence of any SCs within the vast majority of the simulated landscapes (see Fig. 9 in Appendix 3). The number of SCs decreases as the concentration of fruits increases but the relationship seems weaker than in the benchmark (see Fig. 9 in Appendix 3).

Finally, Table 2 compares the potential gains from full-cooperation compared to the NE. Overall, the total profits in the GC are $5.5 \%$ to $19.7 \%$ greater than in the NE and their ratio is positively correlated to the number of SCs. The potential gains from cooperation decrease with $\alpha$ : cooperation is particularly interesting when the density of pollinators is low (see also Figure 10 in Appendix). Figure 10 illustrates that the potential gains from cooperation increases as the spatial autocorrelation increases, at least for medium and high $\alpha$ and medium and low $\beta$ (i.e. when the pollinator abundance increases). The potential benefits are remarkably stable over the different landscapes when the density of pollinator is low (see Figure 10). Given that our main results remain identical among the alternative parametrizations of the ecological function, we keep $\alpha=\beta=0.2$ for the following.

\subsection{Policy Instruments}

\subsubsection{Per-Hectare Payments}

Table 3 displays the conservation and cooperation outcomes for the per-hectare payments from $€ 0 /$ ha to $€ 300 / \mathrm{ha}$. As expected, the payments tend to increase the average total profits 
Fig. 3 a number of SCs per landscape, b size of the SCs, $\mathbf{c}$ share of the SCs composed only of neighbouring farms, $\mathbf{d}$ ratio of the total profits of the GC over the $\mathrm{NE}$ (full black dot) and ratio of the average total profits of the SCs over the NE (open black dot), e share of fruits for members of SCs (full black dot) and for the non-members (open black dot) and $\mathbf{f}$ share of arable plots devoted to habitats crops for the SC members (full black dot) and for the non-members (open black dot) as a function of the landscape's Moran's I. The standard deviations are displayed in the bar when appropriated and are clustered on the landscape's SCs

and habitat areas. The total profit increases as the subsidies increase, but more than the total payments. For $€ 300 /$ ha, the total payments represent $€ 10,790$ (i.e. $2.5 \%$ of the total profit) while the profits increased by $€ 46,532$ compared to a non-policy context. The new incentives lead to more habitats that provide additional pollinators and, ultimately, increase the fruit profitability for all of the farms.

The per-hectare payments reduce the incentives to cooperate for the pollination service (Table 3): there is a continuous decrease in the number of SCs from $€ 0 /$ ha $(4.14$ SCs per landscape) to $€ 120 /$ ha (0.78 SCs per landscape). After this level, there are almost no more SCs. The SCs remain of size two. The difference in profits between members and non-members decreases as the payments increase (and even becomes negative as the rare SCs are composed of farm f1), which underpins the lower willingness to cooperate. This loss of interest in cooperation is due to two combined factors. First, the public payments benefit both the members and non-members. If high enough, the payments reduce the gap between the profits of the members and non-members, and the stability conditions are affected. Second, the additional habitats increase the pollination service, which decreases the interest in the cooperative management of pollinators: farmers tend to free-ride on the contributions of the others.

Figure 4 displays the evolution of the average habitat area depending on the payments. It illustrates that the habitat area moves closer from the SC to the NE as the payments increase between $€ 0 /$ ha to $€ 140 /$ ha (because the number of SC decreases - see Table 3). Indeed, as there are no more SCs after $€ 140 /$ ha (except for 2 to 6 of the 81 simulated landscapes - see Table 3), ${ }^{15,16}$ the only possible landscapes after this threshold are the ones under the NE, which are characterised by the smallest habitat area. As a result, we observe a small decrease in the average habitat area in this payment range. Thus, even if the perhectare payment increases the habitat area within the NE, the average effect of the payment is locally negative because the payment decreases the stability of coalitions that initially conserved more habitats. In other words, the extensive margin effect offsets the intensive margin effect in this range of payments. The per-hectare payment needs to be at least $€ 165 /$ ha to reach again the levels reached at $€ 140 /$ ha (Fig. 4). Finally, there is no clear relationship between the spatial structure and the cooperation outcomes (not displayed). The main difference with Sect. 4.1. is that the SCs are exclusively composed of neighbours.

\subsubsection{The Minimum Participation Rule}

Table 4 displays the results for the MPR simulations. The MPR scheme is composed of a lump-sum payment $Q^{M P R}$ that is paid if the amount of habitats within the coalition exceeds the threshold $\bar{e}$. Because the minimum threshold that we consider is $\bar{e}=20 \%$, the MPR does not affect the NE outcomes (the size of a single farm is smaller than the threshold).

\footnotetext{
15 These landscapes are characterized by a Moran's I higher than 0.2 .

16 Note that, if this threshold appears to be $€ 140 /$ ha on Fig. 4, this threshold is reached for per hectare payments of about $€ 60 /$ ha in some simulated landscapes.
} 

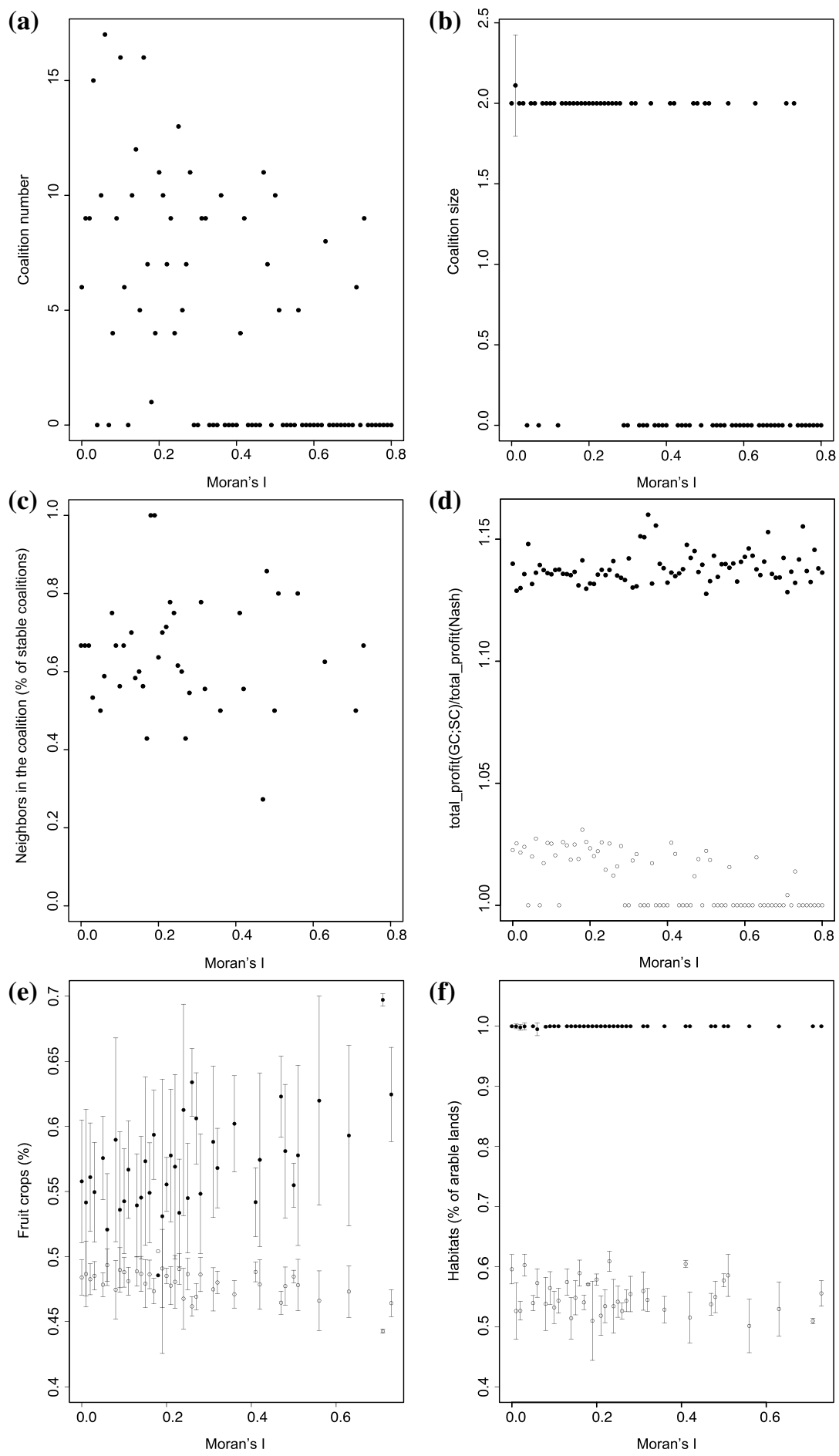
Table 2 Number and size of the stable coalitions for alternative parametrizations of the ecological function $(\mathrm{N}=81)$

\begin{tabular}{|c|c|c|c|c|}
\hline & Number SC & Size SC & $\begin{array}{l}\text { Share } \\
\text { neighbours } \\
\text { in SC }\end{array}$ & $\begin{array}{l}\text { Profits GC/ } \\
\text { Profits NE }\end{array}$ \\
\hline \multirow[t]{2}{*}{$\alpha=0.1$ and $\beta=0.1$} & 2.19 & 2.00 & 0.66 & 1.197 \\
\hline & $(1.65)$ & $(0.00)$ & $(0.29)$ & $(0.001)$ \\
\hline \multirow[t]{2}{*}{$\alpha=0.2$ and $\beta=0.1$} & 0.84 & 2.00 & 0.72 & 1.148 \\
\hline & (4.13) & $(0.00)$ & $(0.34)$ & $(0.017)$ \\
\hline \multirow[t]{2}{*}{$\alpha=0.3$ and $\beta=0.1$} & 0.00 & - & - & 1.055 \\
\hline & $(0.00)$ & & & $(0.031)$ \\
\hline \multirow{2}{*}{$\alpha=0.1$ and $\beta=0.2$} & 0.74 & 2.25 & 0.67 & 1.108 \\
\hline & $(0.89)$ & $(0.39)$ & $(0.40)$ & $(0.001)$ \\
\hline \multirow[t]{2}{*}{$\alpha=0.2$ and $\beta=0.2$} & 4.14 & 2.00 & 0.64 & 1.138 \\
\hline & $(5.00)$ & $(0.00)$ & $(0.16)$ & $(0.006)$ \\
\hline \multirow[t]{2}{*}{$\alpha=0.3$ and $\beta=0.2$} & 0.05 & 2.00 & 1.00 & 1.065 \\
\hline & $(0.22)$ & $(0.00)$ & $(0.00)$ & $(0.020)$ \\
\hline \multirow[t]{2}{*}{$\alpha=0.1$ and $\beta=0.3$} & 0.26 & 2.81 & 0.73 & 1.055 \\
\hline & $(0.65)$ & $(0.40)$ & $(0.44)$ & $(0.001)$ \\
\hline \multirow[t]{2}{*}{$\alpha=0.2$ and $\beta=0.3$} & 2.84 & 2.04 & 0.74 & 1.113 \\
\hline & $(2.12)$ & $(0.15)$ & $(0.26)$ & $(0.004)$ \\
\hline \multirow[t]{2}{*}{$\alpha=0.3$ and $\beta=0.3$} & 0.02 & 2.00 & 0.50 & 1.071 \\
\hline & $(0.22)$ & $(0.00)$ & $(0.00)$ & $(0.012)$ \\
\hline
\end{tabular}

The displayed figures are the averages over the 81 simulated landscapes. The standard deviations are within brackets and are clustered at the landscape level. "Number SC" is the number of SCs per simulated landscape. "Size SC" provides information on the average number of members per SCs. "Share neighbours in SC" presents the share of the SCs composed exclusively of neighbours. "Profits GC/ Profits $\mathrm{NE}$ " is the ratio of the total profit at the landscape scale for the GC over the NE

The MPR scheme could, however, affect the formation of larger coalitions. Indeed, a low MPR threshold (20\%) decreases the external stability of the 2-farmers coalitions, which are no longer stable (Table 4). They are replaced by larger coalitions, which grow as the lump-sum payment increases but which are less frequent. The GC is even reached for a lump-sum payment of $€ 800$ in some of the simulated landscapes. These new coalitions usually conserve more habitats than the initial coalitions (for lump-sum payments higher than €500), but also sometimes less (for lump-sum payments equal to €200). As for the per-hectare payments, an increase in the lump-sum payments can thus decrease the conserved habitats at the margin. After a threshold, an increase in the lump-sum payments increases the conservation efforts, at least when $\bar{e}$ is low.

The effects of the lump-sum payments depend indeed on the levels of $\bar{e}$. For example, the coalitions of two or three farmers cannot easily reach a threshold of $50 \%$ or $80 \%$ and 


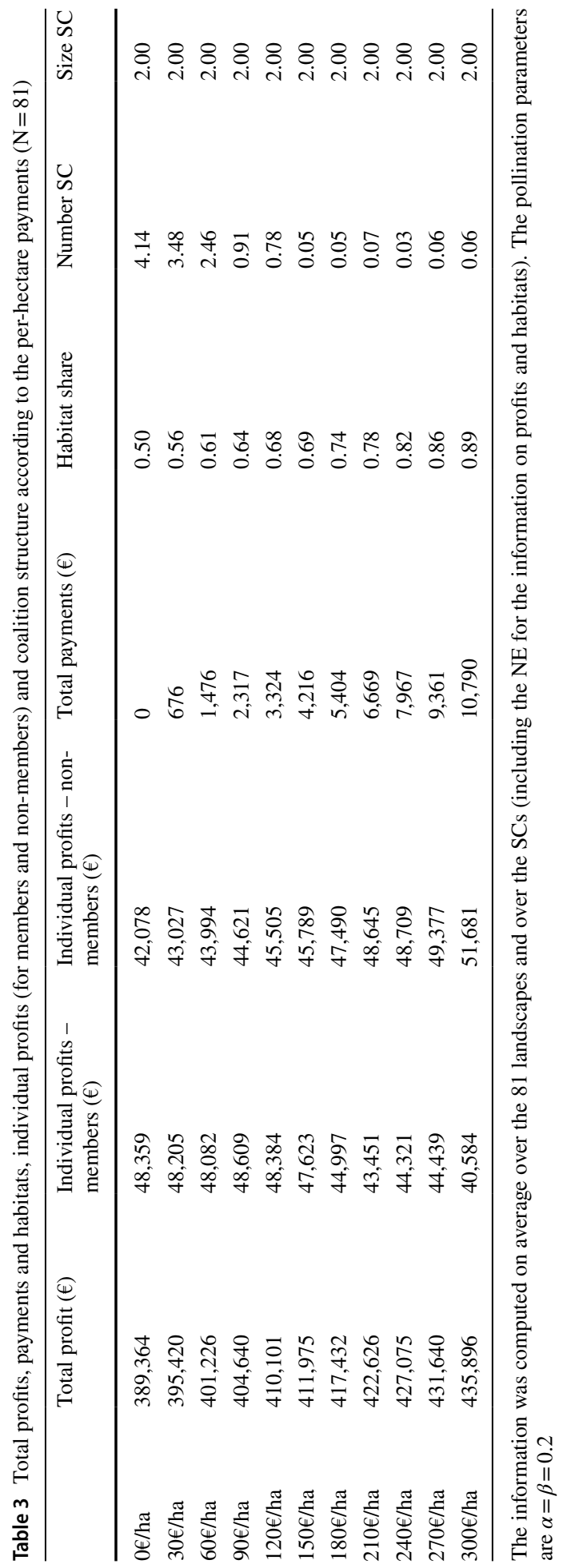




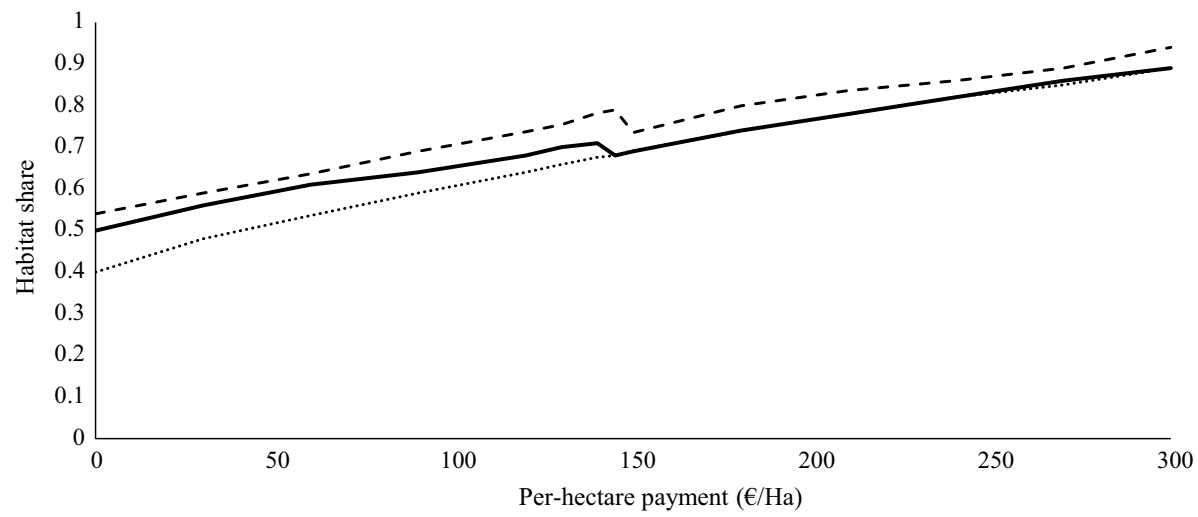

Fig. 4 Average share of arable lands covered by habitats according to per-hectare payments within all SCs (solid line), the Nash equilibrium (dotted line) and the SCs with at least two farmers (dashed line)

Table 4 Total profits, payments and habitats, individual profits (for members and non-members) and coalition structure according to the MPR threshold rates and lump-sum payments $(\mathrm{N}=81)$

\begin{tabular}{|c|c|c|c|c|c|c|c|}
\hline & $\begin{array}{l}\text { Total profit } \\
(€)\end{array}$ & $\begin{array}{l}\text { Individual } \\
\text { profits - } \\
\text { members }(€)\end{array}$ & $\begin{array}{l}\text { Individual } \\
\text { profits - non- } \\
\text { members }(€)\end{array}$ & $\begin{array}{l}\text { Total } \\
\text { payments } \\
(€)\end{array}$ & Habitat share & Number SC & Size SC \\
\hline $0 €$ & 389,364 & 48,359 & 42,078 & 0 & 0.50 & 4.14 & 2.00 \\
\hline \multicolumn{8}{|c|}{ MPR threshold of $20 \%$} \\
\hline$€ 200$ & 385,491 & 54,487 & 36,054 & 300 & 0.46 & 0.80 & 3.59 \\
\hline$€ 500$ & 393,276 & 52,351 & 31,838 & 1,444 & 0.53 & 1.00 & 5.78 \\
\hline$€ 800$ & 400,453 & 51,370 & 27,434 & 2,883 & 0.59 & 1.00 & 7.21 \\
\hline$€ 1100$ & 404,964 & 51,012 & 24,357 & 4,318 & 0.63 & 1.00 & 7.85 \\
\hline \multicolumn{8}{|c|}{ MPR threshold of $50 \%$} \\
\hline$€ 200$ & 389,355 & 48,379 & 42,072 & 0 & 0.50 & 4.12 & 2.00 \\
\hline$€ 500$ & 391,424 & 49,371 & 41,537 & 310 & 0.52 & 4.65 & 2.52 \\
\hline$€ 800$ & 394,266 & 49,696 & 41,286 & 919 & 0.54 & 5.06 & 3.00 \\
\hline$€ 1100$ & 395,713 & 49,664 & 41,397 & 1,403 & 0.55 & 5.09 & 3.14 \\
\hline \multicolumn{8}{|c|}{ MPR thresold of $80 \%$} \\
\hline$€ 200$ & 389,355 & 48,379 & 42,072 & 0 & 0.50 & 4.12 & 2.00 \\
\hline$€ 500$ & 389,620 & 48,455 & 42,045 & 29 & 0.50 & 4.16 & 2.06 \\
\hline$€ 800$ & 392,187 & 48,823 & 41,918 & 439 & 0.53 & 4.49 & 2.51 \\
\hline$€ 1100$ & 394,443 & 49,105 & 41,833 & 1,006 & 0.54 & 4.75 & 2.84 \\
\hline
\end{tabular}

The information was computed on average over the 81 landscapes and over the SCs (including the NE for the information on total profits and habitats). The pollination parameters are $\alpha=\beta=0.2$

are thus not affected by the scheme. More specifically, these coalitions are not easily disrupted by the lump-sum payments and hence mostly remain stable (Table 4). Because high threshold levels do not easily undermine the external stability of the existing SCs, setting overly high threshold levels do not yield results that are substantially different from the Benchmark. Interestingly, for high lump-sum payments (€500 or €800), increasing the 


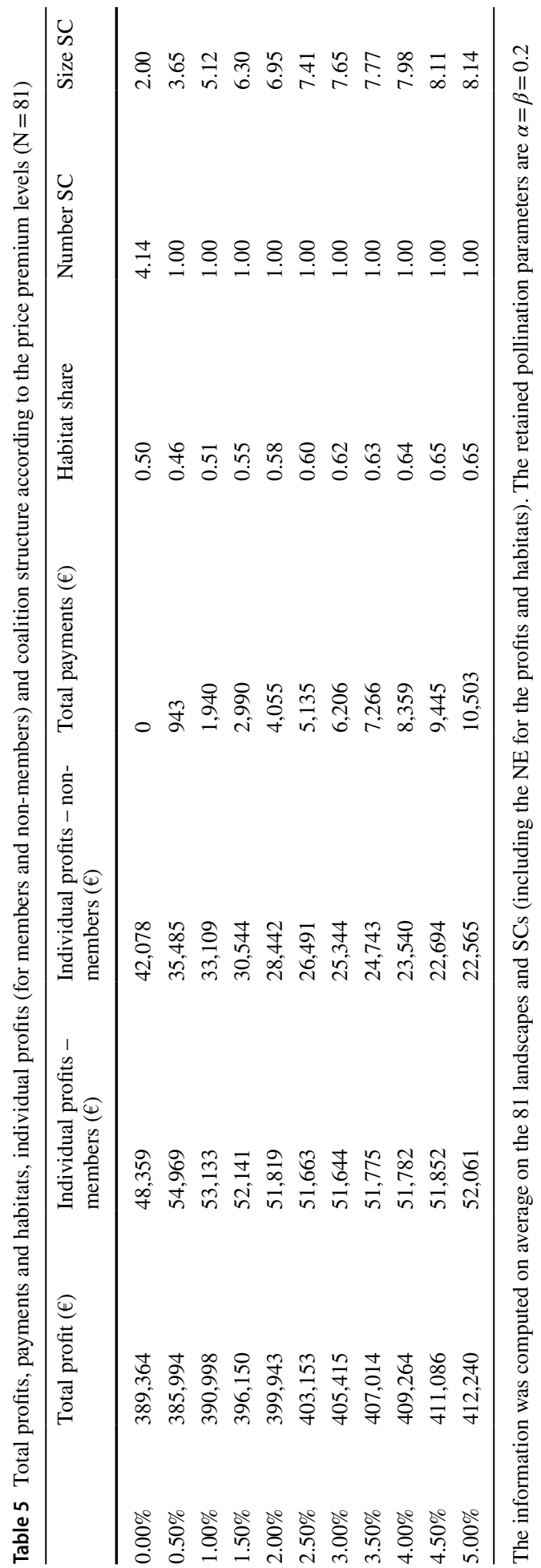


MPR rate from $20 \%$ to $50 \%$ or $80 \%$ decreases on average the habitat area: the rare new SCs initially conserved less habitats than the original SCs. The additionality of lump-sum payments is thus higher for low threshold levels. Finally, it should be noted that the MPR can also - slightly - increase the profitability of farming. For example, the profits (excluding payments) increase by about $0.1 \%$ in the case of the $€ 500$ lump-sum payment coupled with a MPR rate of 0.8 compared to the benchmark case.

\subsubsection{The Price Premium for Cooperative Management}

Table 5 displays the results for the simulations with the price premium, from $+0 \%$ to $+5 \%$ of the initial price. An increase in the premium decreases the number of SCs as the added value of cooperation created by the price premium undermines the external stability of many coalitions, but quickly increases their size. As expected, the price premiums increase the average total profits, in particular those of the coalition members (by design, the price premium does not directly affect the profits of singletons). Interestingly, the average habitat area decreases from a premium of $0 \%$ to $0.5 \%$ due to the higher amplitude of the negative effect at the extensive margin (the disruption of the original SCs) compared to the beneficial effect at the intensive margin. The GC starts to be the unique SC in some landscapes for premiums of $1.5 \%$. The GC remains the single SC for 29 of the 81 simulated landscapes for a price premium of 5\%, and in this case, all arable lands are devoted to habitats. Finally, we find that price premiums increase the average profitability of farming (since the price premiums are higher than 1.5\%): the profits without the premiums are higher than in the Benchmark. This result is stronger and more robust than with the MPR program, but less than the per-hectare payments.

Contrary to the other instruments, the effect of the price premium on the cooperation outcomes is affected by the landscape structure. For example, for a price premium of 5\%, the $\mathrm{GC}$ is stable in $62 \%$ of the landscapes in the first spatial autocorrelation quartile (for a Moran's I between 0 and 0.2 ), in $45 \%$ of the landscapes in the second quartile, in $25 \%$ of the landscapes in the third quartile and only in $10 \%$ of the landscapes in the fourth quartile (for a Moran's I between 0.61 and 0.8). Indeed, because the price premium only affects the gains for cooperating farms and as the potential gains from cooperation are less important for high spatial autocorrelation (see Sect. 4.1.), the GC is more likely to be stable for low Moran's I. This is particularly true for low price premiums. For example, the GC is stable 10 times for a price premium of $2.5 \%$, but only for Moran's I lower than 0.2 . At a similar premium level and when the Moran's I is higher than 0.6 , farms $\mathrm{f} 1$, $\mathrm{f} 2$ and $\mathrm{f} 3 \mathrm{do}$ not cooperate with the others, as these farms present sensibly lower levels of fruits when the spatial autocorrelation is high. Because the price premium depends heavily on the cooperation processes, its increase thus affects differently the conservation outcomes depending on the spatial structure.

\subsubsection{Budget-Effectiveness of the three Instruments}

Tables 3, 4, 5 display the detailed responses to the different policies in terms of land-use choices within the coalitions (the intensive margin effects) and the stability of the alternative coalitions (the extensive margin effects). However, the results are available per levels of payments, which prevents simple comparisons of the budget-effectiveness of the alternative instruments. Figure 5 displays the share of habitats at the landscape scale according to the 


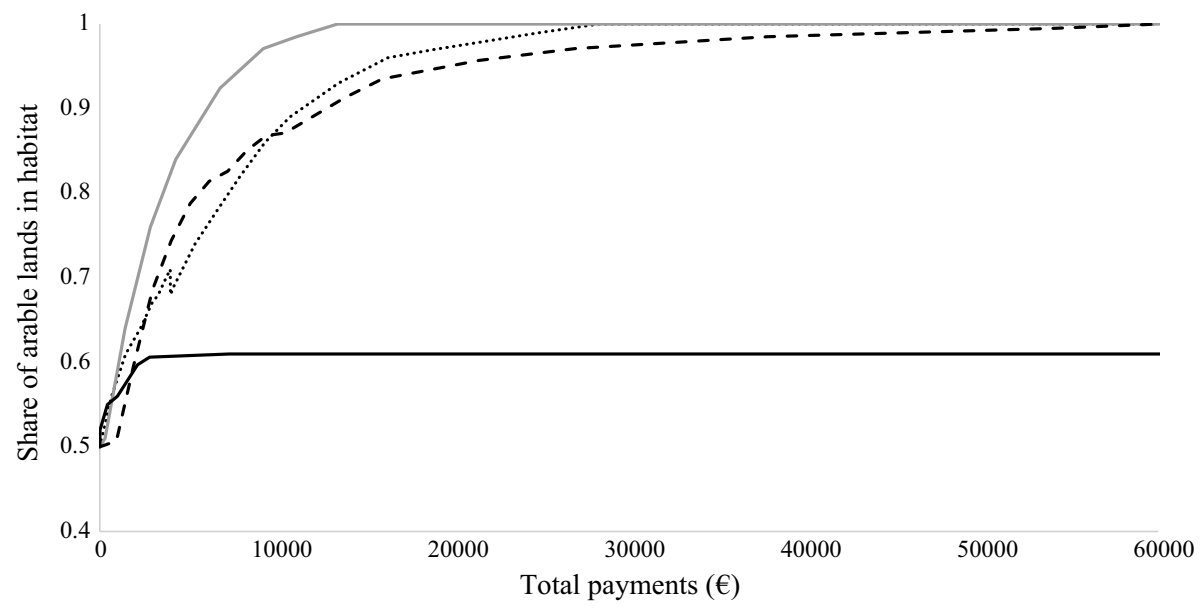

Fig. 5 Average share of arable lands devoted to habitats according to the total payments (in $€$ ), the perhectare payments (dotted line), the price premium (dashed line), the MPR with a threshold of 20\% (solid grey line) and the MPR with a threshold of 50\% (solid black line). The averages were computed on the 81 simulated landscapes and on (i) the SCs with at least two farmers for the MPR and price premium, and (ii) all SCs for the per-hectare payments (which also include the NE)

total expenditures of the alternative policies. Compared to Tables 4 and 5, we only display the results for the SCs with at least two farmers for the collective instruments (i.e. the MPR and the price premium). ${ }^{17,18}$ The MPR with a threshold $\bar{e}$ of $20 \%$ is the most efficient instrument on average (Fig. 5). This is due to the highest extensive margin effect for these levels of lumpsum payments and this threshold level. However, increasing the threshold levels decreases the budget-effectiveness of the MPR because the previously stable coalitions cannot reach $\bar{e}$ and remain insensitive to the increase in the payments. In terms of budget-effectivenness, the MPR with high thresholds are the worst simulated instruments. This illustrates, if needed, the careful attention that is required by policymakers to design policy instruments. The per-hectare payments have an intermediate budget-effectivenness. Interestingly, the evolution of the habitat area with the aggregated payments display a similar pattern to the one in Fig. 4, with a temporary drop when the initial SCs are disrupted by the payments. The price premium is, on average, almost as efficient as the per-hectare payments.

Figure 6 plots the total habitats according to the total payments in the four quartiles of Moran's I. The spatial correlation of the fruit areas affects the budget-effectiveness of the policy instruments. First, if the MPR with low thresholds are always the most budget-effective instrument and the MPR with high thresholds are always the worst ones, an increase in the fruit concentration reduces the budget-effectiveness of the MPR with low thresholds, but increases the budget effectiveness of the MPR with high thresholds. Second, the budget-effectiveness of the per-hectare payments slightly decreases as the spatial autocorrelation increases.

\footnotetext{
${ }^{17}$ Indeed, because the NE is a stable equilibrium that does not respond to the MPR and the premium, the average outcomes over the SCs tends to be smoothed. In contrast, we keep the NE outcomes for the perhectare payments as the NE remains the single stable equilibrium in the majority of landscapes after levels of $€ 140 /$ ha.

${ }^{18}$ We do not plot the MPR with a threshold of $80 \%$ as the curve is almost identical to the MPR with a threshold of $50 \%$.
} 
(a)

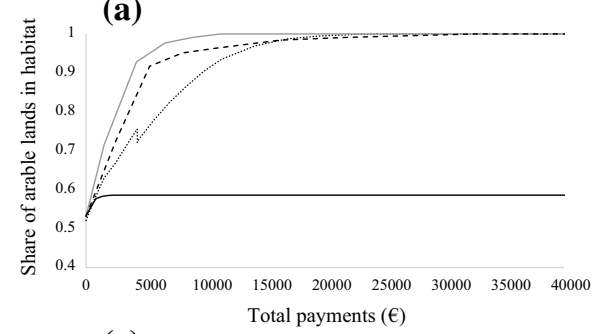

(c)

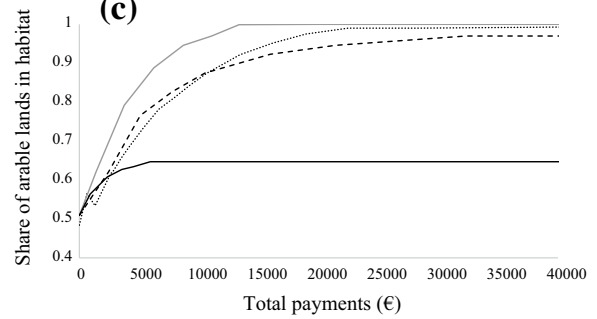

(b)

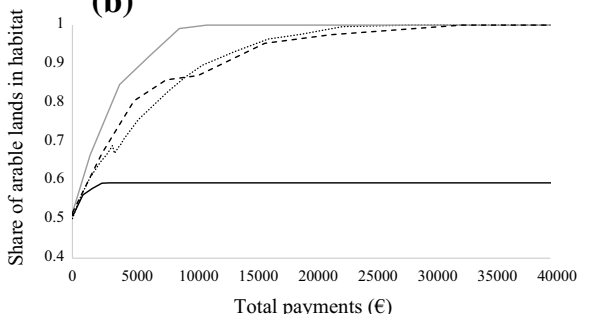

(d)

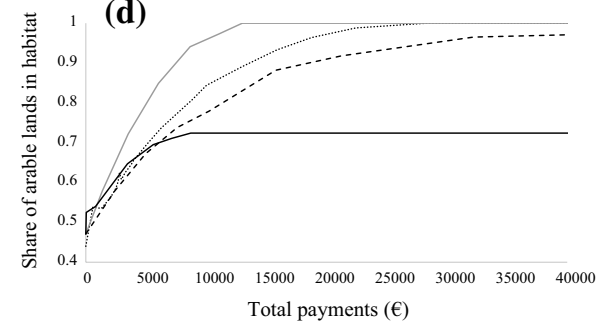

Fig. 6 Average share of arable lands devoted to habitats according to the total payments (in $€$ ), the per-hectare payments (dotted line), the price premium (dashed line), the MPR with a threshold of $20 \%$ (solid grey line) and the MPR with a threshold of $50 \%$ (solid black line) for a the first quartile, $\mathbf{b}$ the second quartile, $\mathbf{c}$ the third quartile and $\mathbf{d}$ the fourth quartile of Moran's I. The averages were computed on the 81 simulated landscapes and on (i) the SCs with at least two farmers for the MPR and price premium, and (ii) all SCs for the per-hectare payments (which also includes the NE)

The temporary drop appears earlier in the total payments as spatial autocorrelation increases, suggesting that SCs are distrupted for smaller payments as the fruit concentration increases. Finally, the budget-effectiveness of the price premium decreases as spatial autocorrelation increases, and to a higher extent than the other instruments. In particular, while its budgeteffectiveness is sensibly higher than the per-hectare payments for low spatial autocorrelation (and about the same than the MPR with low rate - see Fig. 6a), it is less efficient for high spatial autocorrelation (Figs. 6c, d). The interest in the price premium decreases as the fruits are more and more concentrated.

\section{Discussion and Concluding Remarks}

Agricultural production depends on the provision of productive ES that, in turn, are affected by the landscape-scale land use decisions of the same farmers that benefit from them. The literature highlights how the efficient provision of these ES would require the cooperation of all of the farmers in the area. Yet, being delivered by mobile ES providers such as pollinators, cooperation for their conservation is hindered by free-riding problems. Most of the literature has, however, either assumed full- or non-cooperation, ignoring the possibility of partial cooperation. In this paper, we assess to what extent partial cooperation among farmers on pollination management can emerge (in terms of number, size, and composition of the SCs) and how policy instruments can foster it. To do so, we introduce a spatially-explicit bioeconomic model of pollination within a coalition formation game. We also contribute to the literature on coalition formation by considering the case in which the levels of the public good (pollination here) differ within the landscape and among the agents. Indeed, the bulk of the literature has examined the endogenous coalition formation 
by considering cases of pure public good, which, by definition, is identical across agents and localizations.

Specifically, our results show that only $0.25 \%$ to $0.75 \%$ of the possible coalitions are spontaneously stable within the generated landscapes (without any public intervention). Depending on the parametrization of the pollinators' abundance function, the SCs are composed of two or three farmers (out of nine) and are mainly composed of neighbours. The coalition members allocate all of their arable land to habitats, while the non-members still grow annual crops. Not surprisingly, the farmers that have the highest willingness to cooperate are the ones with the largest fruit areas. The central farm has the highest willingness to cooperate, ceteris paribus. We find that average total profits increase by about $2.5 \%$ in the landscapes with a SC, compared to the NE landscapes. Furthermore, despite that the GC leads to the highest total profit, it is never stable without policy intervention. This is a crucial result as the existing studies have assumed its stability (Atallah et al. 2017; Bareille et al. 2020; Cong et al. 2014; Epanchin-Niell and Wilen 2015). Overall, the cooperation for the management of productive ES is possible, but remains partial.

Endogenizing the choice of cooperating is particularly valuable to assess the budgeteffectiveness of agri-environmental policy instruments. Indeed, policy instruments affect the land-use choices of the farmers within one given coalition (i.e. the effect at the intensive margin), but also their choices to join a coalition (i.e. the effect at the extensive margin). Accordingly, we provide new insights on usual conservation instruments when the targeted habitats support both public good valued by society (the existence value of biodiversity) and farmers (the pollination service). First, we find that an increase in the perhectare payments does not necessarily lead to more conserved habitats. Indeed, the intensive margin effect may be offset by the extensive margin effect for some payment levels: the per-hectare payments disrupt the stability of coalitions that initially conserved more habitats. This is a striking result as the literature usually ignores the extensive margin effect of policy instruments on cooperation for productive ES and, as a result, finds that the perhectare payments always increase the conservation of habitats. Second, we find that setting a high MPR threshold may be counterproductive as SCs are not disrupted by the lumpsum payments; policymakers should instead take advantage of the coalition formation process to foster conservation. Indeed, setting a MPR threshold at a level close to the one reached within the existing SCs decreases their external stability and fosters the creation of larger coalitions that conserve more habitats. This result does not appear in the literature on MPR schemes as the authors assume the stability of the GC (e.g., Dupraz et al. 2009). On average, the MPR with a low threshold is the most efficient instrument, but needs to be carefully designed. Finally, our paper provides an evaluation of the budget-effectiveness of a price premium for farms involved in cooperative pollination management. To our knowledge, such an instrument has not been studied previously in the literature despite some examples of its utilization in real life settings. ${ }^{19}$ Our simulations illustrate that the price premium increases the stability of large coalitions (in particular the GC), leading to a high level of conserved habitats. All of the simulated instruments improve the agricultural

\footnotetext{
19 A similar scheme is used by some food companies, such as Barilla® in Italy or LUß in France, to maintain wild pollinators (independently of cooperative management though). These companies increase their product price so that the additional benefits are redistributed to their suppliers - i.e. the farmers - that grow flowers on parts of their arable lands.
} 
profitability in some range of payments, by fostering the stability of large Pareto-improving coalitions that provide more pollinators.

Our work also explores the role of the landscape structure on the cooperative outcomes and the resulting conserved habitat and agricultural profitability. We generated landscapes with half of the area devoted to fruits but for which the spatial autocorrelation differed (with Moran's I going from 0 to 0.8). We find that the number of SCs and the cooperation benefits decrease as the spatial autocorrelation increases. The spatial autocorrelation also affects the effectiveness of the policy instruments, in particular the price premium, which is more effective than the per-hectare payments for low spatial autocorrelation, but less effective when the spatial autocorrelation is high.

If our method presents some advances with regard to the existing literature, our work still suffers from several limitations. First, we have considered a short-term maximization and ignored the dynamic of pollinator abundance and related long-term choices. In particular, we have assumed that the area devoted to fruits was exogeneous. However, the increase in the pollinator density under cooperative management increases the profitability of fruit production and thus should provide incentives to farmers to increase the fruit areas in the long-term. Second, we did not account for coordination costs. To our knowledge, these costs have never been accounted for in the literature on the coordinated management of mobile ES providers. The integration of coordination costs are, however, suspected to affect the stability of the different coalitions (Banerjee et al. 2017). Third, we only considered policy instruments that reward the farmers individually for their collaborative performance (e.g. the MPR or the price-premium). We did not analyse any instruments that reward collaborative solutions per se by providing an aggregated payment for the group (Kotchen and Segerson 2019). Such types of payments would, however, raise the additional question of the distribution of the payments among the SC's members (Drechsler 2017). The possibility for side-payments, with or without any policy instruments, is suspected to modify our conclusions as it would increase the stability of the biggest coalitions, even with heterogeneous agents (Bakalova and Eyckmans 2019). Finally, we have assumed that the productivity of pollination was constant, entailing orthogonal reaction function. This implies that farmers' choice of land allocation is not affected by the choice of the other farmers. Even if this assumption is not uncommon, diminishing returns to pollinations arise in real landscapes, which should change the cooperation outcomes. In particular, a two-farmers coalition should no longer be stable, but replaced by NE or by larger coalitions (Carraro and Marchiori 2002). The effect of the policies might also differ accordingly. There is thus noteworthy space for improvement and future studies on the cooperative management of productive ES should focus on these dimensions. 


\section{Appendix A}

To prove that the game is a positive externality game, consider a non-coalition member $h$. For any $h \notin \mathbf{S}$, the utility for a non-coalition member $i \notin \mathbf{S}$ when the coalition composition is $\mathbf{S}$ is (slightly reshaping for clarity Eq. (9)):

$$
\begin{aligned}
\Pi_{i}^{n s, *}(S)= & \pi^{a} \cdot\left(1-f_{i}-e_{i}^{n s}\right)-\frac{1}{2} \cdot c \cdot\left(1-f_{i}-e_{i}^{n s}\right)^{2} \\
& +f_{i} \cdot p_{i}^{f} \cdot y^{f} \cdot b \cdot\left(e_{i}^{n s} \cdot \alpha+\sum_{\substack{z \neq i \\
z \in S}}^{I} \bar{e}_{z}^{s}(S) \cdot \alpha \cdot \exp ^{-\beta \cdot d_{i z}}+\sum_{\substack{j \neq i \\
j \notin S}}^{I} \bar{e}_{j}^{n s} \cdot \alpha \cdot \exp ^{-\beta \cdot d_{i j}}+\bar{e}_{h}^{n s} \cdot \alpha \cdot \exp ^{-\beta \cdot d_{i h}}\right) \\
& -f_{i} \cdot C^{f}+f_{i} \cdot p_{i}^{f} \cdot y^{f} \cdot a
\end{aligned}
$$

In (A.1) $e_{i}^{n s}$ is the own contribution to the pollinator habitat of farmer $i$, the second term within brackets is the contribution of the coalition members, and the third and fourth terms are, respectively, the contribution of non-members excluding farmer $h$, and the contribution of the non-coalition member farmer $h$.

From (6) note that $e_{i}^{n s}(S)=e_{i}^{n s}(S \cup h)$, i.e. the coalition size and composition do not affect the contribution of a singleton farmer - and hence we remove the brackets hereinafter. Instead, $e_{z}^{s}(S)>e_{z}^{s}(S \cup h)$. Compare (13) with:

$$
e_{z}^{s}(S \cup h)=\frac{-\pi^{a}+f_{h} \cdot\left(p_{h}^{f} \cdot \bar{y}^{f} \cdot b \cdot \alpha \cdot \exp ^{-\beta \cdot d_{z h}}\right)+\sum_{k \in S}^{I} f_{k} \cdot\left(p_{k}^{f} \cdot \bar{y}^{f} \cdot b \cdot \alpha \cdot \exp ^{-\beta \cdot d_{z k}}\right)}{c}+\left(1-f_{z}\right)
$$

Moreover, we already noted that $e_{h}^{s}(\mathbf{S})>e_{h}^{n s}$. Finally, note that $\Pi_{i}^{n s, *}(\mathbf{S} \cup h)$ is given by:

$$
\begin{aligned}
\Pi_{i}^{n s, *}(S \cup h)= & \pi^{a} \cdot\left(1-f_{i}-e_{i}^{n s}\right)-\frac{1}{2} \cdot c \cdot\left(1-f_{i}-e_{i}^{n s}\right)^{2}+f_{i} \cdot p_{i}^{f} \cdot y^{f} \cdot b \cdot \\
& \left(e_{i}^{n s} \cdot \alpha+\sum_{\substack{z \neq \neq \\
z \in S}}^{I} \bar{e}_{z}^{s}(\mathbf{S} \cup h) \cdot \alpha \cdot \exp ^{-\beta \cdot d_{i z}}+\sum_{\substack{j \neq i \\
j \notin S}}^{I} \bar{e}_{j}^{n s} \cdot \alpha \cdot \exp ^{-\beta \cdot d_{i j}}+\bar{e}_{h}^{s}(\mathbf{S} \cup h) \cdot \alpha \cdot \exp ^{-\beta \cdot d_{i h}}\right) \\
& -f_{i} \cdot C^{f}+f_{i} \cdot p_{i}^{f} \cdot y^{f} \cdot a
\end{aligned}
$$

As the optimal land allocated to habitat for non-member of the coalition is not affected by the coalition size, the only differences between (A.3) and (A.1) are in the terms within brackets. The first and the third terms inside the brackets are the same in the two equations. The second term is greater in (20) than in (18) since $e_{z}^{s}(\mathbf{S})>e_{z}^{s}(\mathbf{S} \cup h$ ) (see relation (19)). And the fourth term within brackets is also greater in (20) than in (18). Thus, $\Pi_{i}^{n, *}(\mathbf{S} \cup h)>\Pi_{i}^{n, *}(\mathbf{S})$ and the game is a positive externality game.

\section{Appendix B}

Landscape structure across the Moran's I quantiles (Fig. 7). 


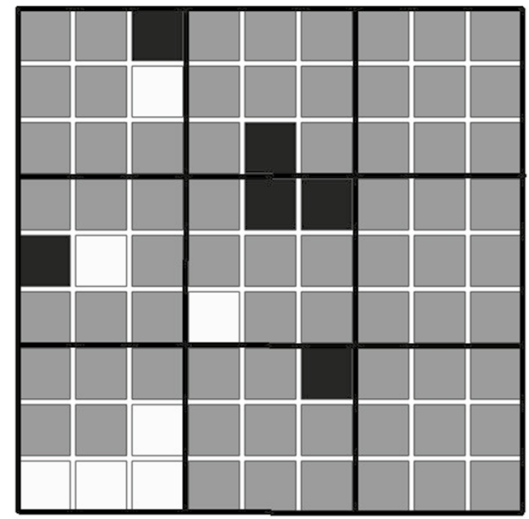

(a)

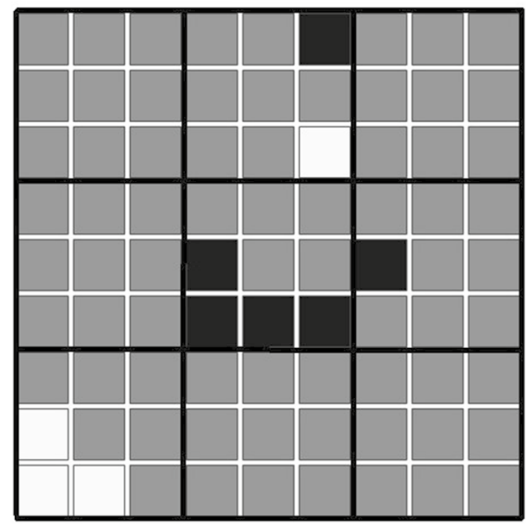

(c)

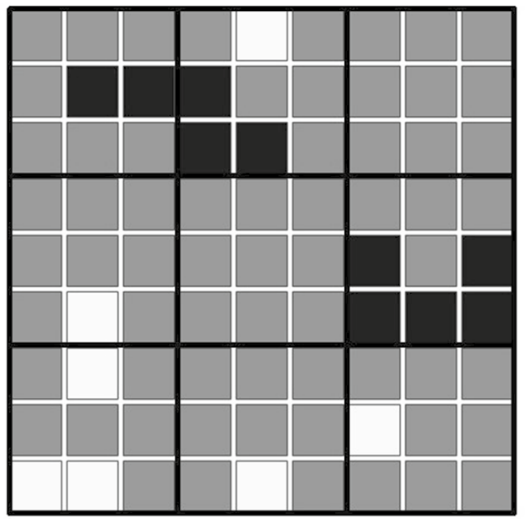

(b)

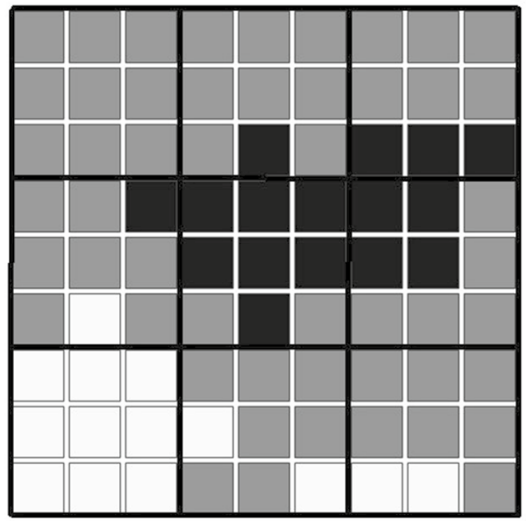

(d)

Fig. 7 Average fruit area per plot for a the first quantile of Moran's $I(I \in[0 ; 0.2])$, b the second quantile of Moran's I $(\mathrm{I} \in[0.21 ; 0.4])$, $\mathbf{c}$ the third quantile of Moran's $\mathrm{I}(\mathrm{I} \in[0.41 ; 0.6])$ and the fourth quantile of Moran's I $(I \in[0.61 ; 8])$

\section{Appendix C}

Sensitivity analysis for the pollinators' aundance function (Figs. 8, 9, 10). 

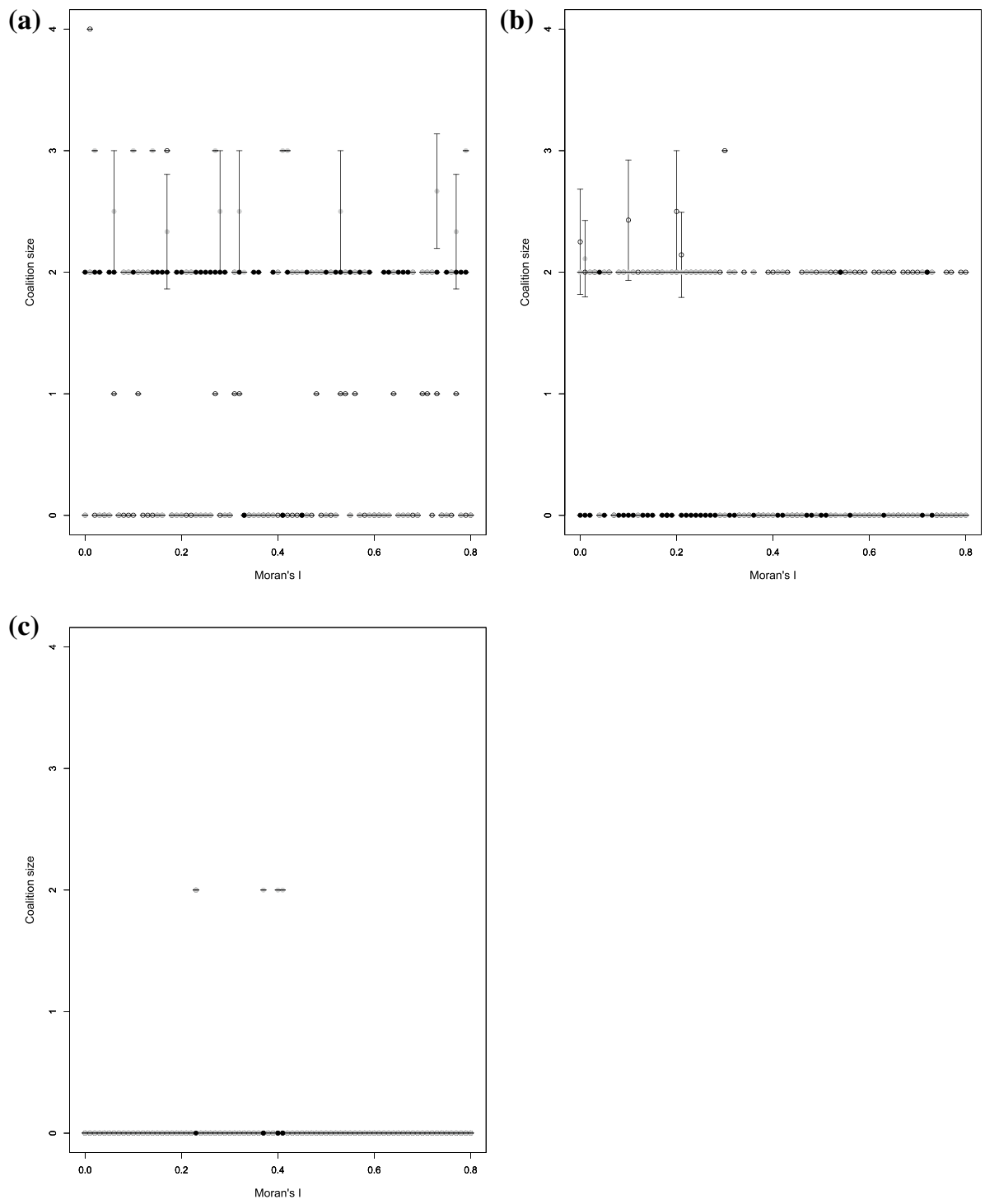

Fig. 8 coalition size per landscape with $\beta=0.1$ (full black dot), $\beta=0.2$ (full grey dot) and $\beta=0.3$ (open black dot) for a $\alpha=0.1, \mathbf{b} \alpha=0.2$ and $\mathbf{c} \alpha=0.3$ 

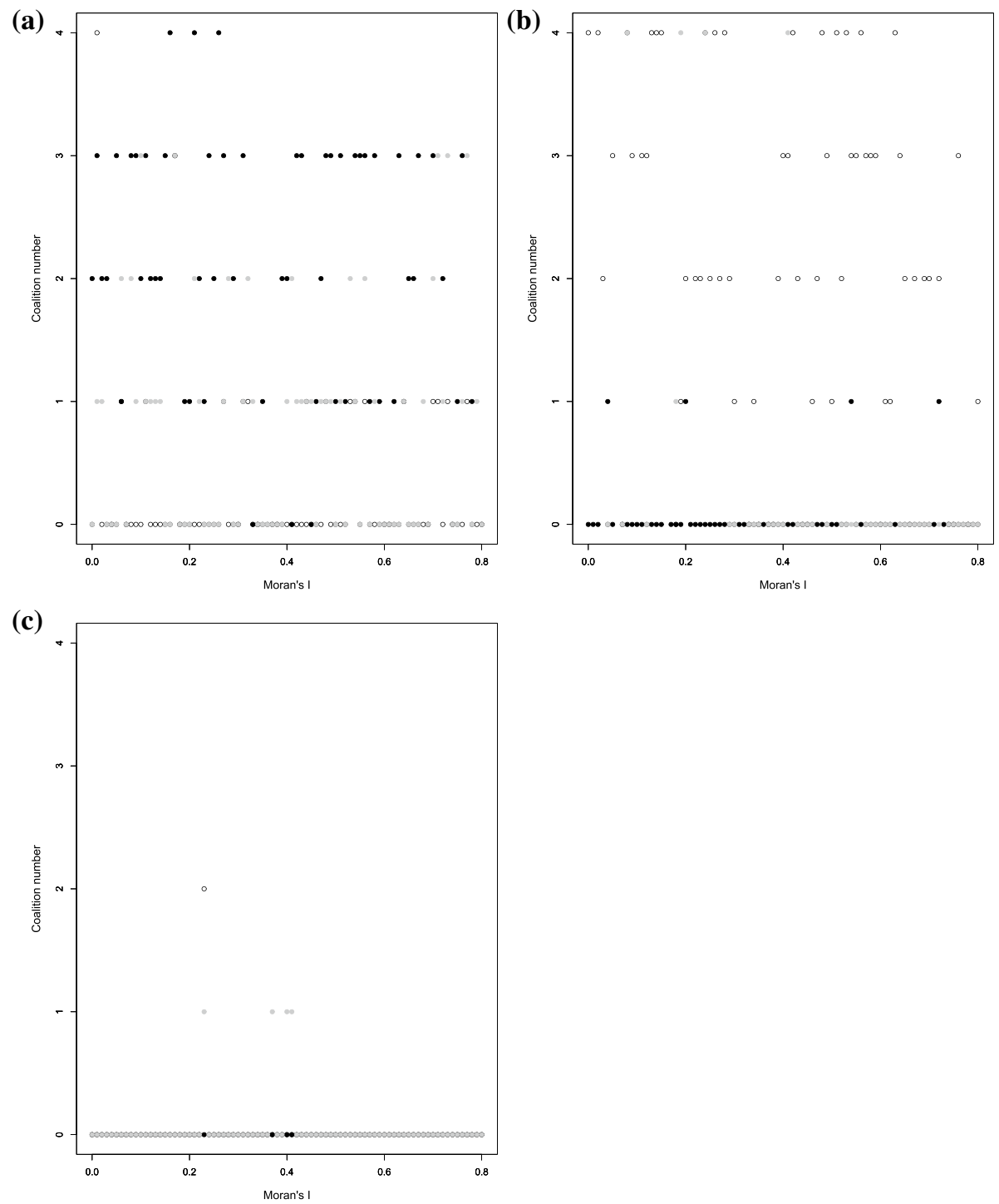

Fig. 9 Number of stable coalitions per landscape with $\beta=0.1$ (full black dot), $\beta=0.2$ (full grey dot) and $\beta=0.3$ (open black dot) for a $\alpha=0.1, \mathbf{b} \alpha=0.2$ and $\mathbf{c} \alpha=0.3$ 

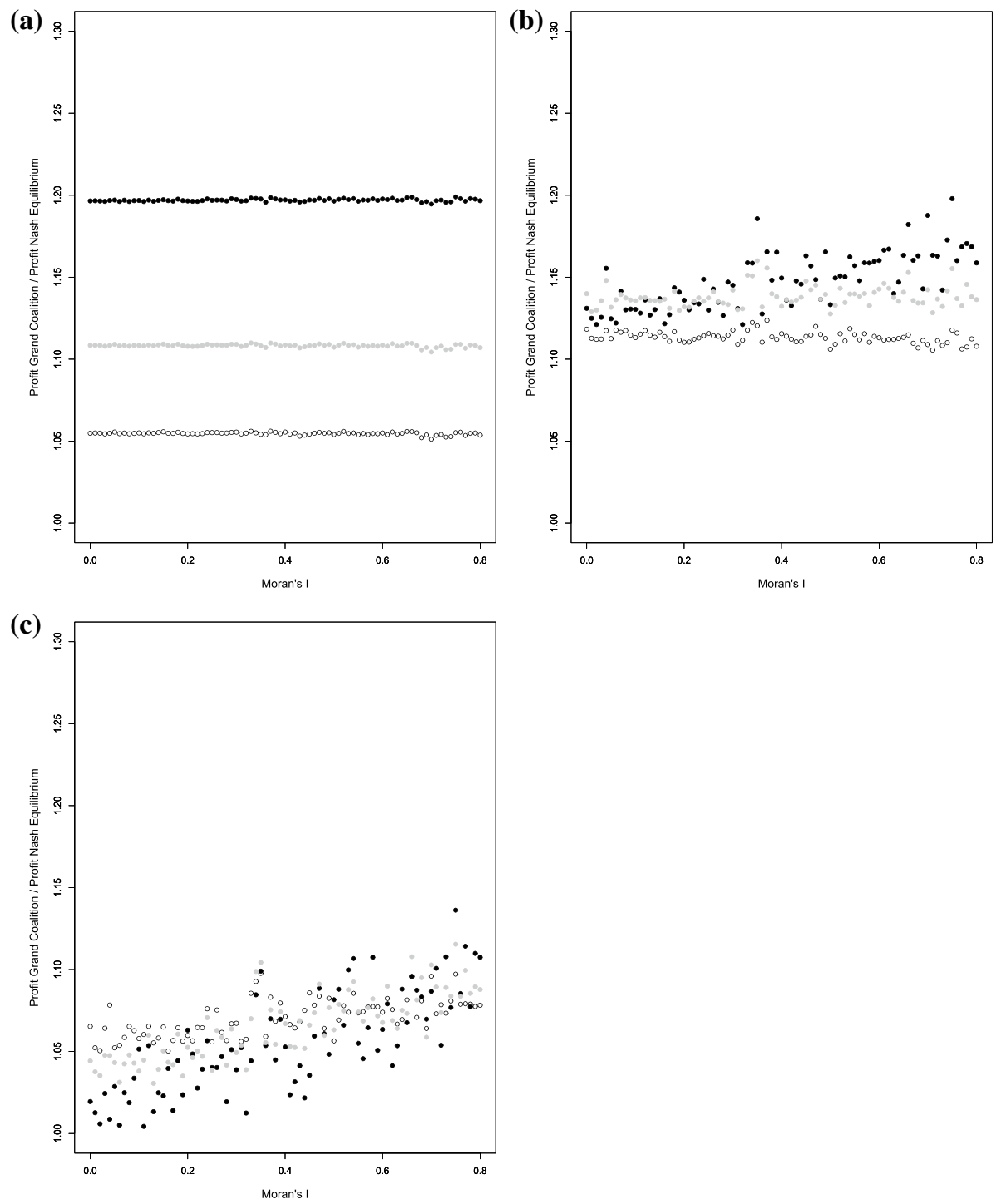

Fig. 10 Ratio of the aggregagted profit in the GC on the NE's aggregated profit with $\beta=0.1$ (full black dot), $\beta=0.2$ (full grey dot) and $\beta=0.3$ (open black dot) for $\mathbf{a} \alpha=0.1, \mathbf{b} \alpha=0.2$ and $c \alpha=0.3$ 
Acknowledgements The authors aknowledge three anonymous reviewers for their suggestions that greatly improve the manuscript. The authors thank Basak Bayramoglu for helpful comments on an early version of the work. This paper is part of the LIFT ('Low-Input Farming and Territories - Integrating knowledge for improving ecosystem-based farming') project that has received funding from the European Union's Horizon 2020 research and innovation programme under grant agreement $n^{\circ} 770747$. Francois Bareille also aknowledges support from the Convergence Institute CLAND (https://cland.lsce.ipsl.fr/). This article does not necessarily reflect the view of the EU and in no way anticipates the European Commission's future policy.

Funding Open access funding provided by Alma Mater Studiorum - Università di Bologna within the CRUI-CARE Agreement.

Open Access This article is licensed under a Creative Commons Attribution 4.0 International License, which permits use, sharing, adaptation, distribution and reproduction in any medium or format, as long as you give appropriate credit to the original author(s) and the source, provide a link to the Creative Commons licence, and indicate if changes were made. The images or other third party material in this article are included in the article's Creative Commons licence, unless indicated otherwise in a credit line to the material. If material is not included in the article's Creative Commons licence and your intended use is not permitted by statutory regulation or exceeds the permitted use, you will need to obtain permission directly from the copyright holder. To view a copy of this licence, visit http://creativecommons.org/licenses/by/4.0/.

\section{References}

Albrecht M, Kleijn D, Williams NM, Tschumi M, Blaauw BR, Bommarco R, Campbell AJ, Dainese M, Drummond FA, Entling MH, Ganser D, de Groot GA, Goulson D, Grab H, Hamilton H, Herzog F, Isaacs R, Jacot K, Jeanneret P, Jonsson M, Knop E, Kremen C, Landis DA, Loeb GM, Marini L, McKerchar M, Morandin L, Pfister SC, Potts SG, Rundlöf M, Sardiñas H, Sciligo A, Thies C, Tscharntke T, Venturini E, Veromann E, Vollhardt IMG, Wäckers F, Ward K, Wilby A, Woltz M, Wratten S, Sutter L (2020) The effectiveness of flower strips and hedgerows on pest control, pollination services and crop yield: a quantitative synthesis. Ecol Lett 23:1488-1498

Alvarado-Quesada I, Weikard H-P (2017) International cooperation on biodiversity conservation when spatial structures matter. Spat Econ Anal 12:27-49

Ansink E, Bouma J (2013) Effective support for community resource management. Forest Policy Econ 37:94-103

Atallah SS, Gómez MI, Conrad JM (2017) Specification of spatial-dynamic externalities and implications for strategic behavior in disease control. Land Econ 93:209-229

Bakalova I, Eyckmans J (2019) Simulating the impact of heterogeneity on stability and effectiveness of international environmental agreements. Eur J Oper Res 277:1151-1162

Banerjee S, Cason TN, de Vries FP, Hanley N (2017) Transaction costs, communication and spatial coordination in payment for ecosystem services schemes. J Environ Econ Manag 83:68-89

Bareille F, Letort E (2018) How do farmers manage crop biodiversity? A dynamic acreage model with productive feedback. Eur Rev Agric Econ 45:617-639

Bareille F, Boussard H, Thenail C (2020) Productive ecosystem services and collective management: lessons from a realistic landscape model. Ecol Econ 169:106482

Barrett S (1994) Self-enforcing international environmental agreements. Oxford Econ Papers New Ser 46:878-894

Bayramoglu B, Finus M, Jacques J-F (2018) Climate agreements in a mitigation-adaptation game. J Public Econ 165:101-113

Bloch F (1995) Endogenous structures of association in oligopolies. Rand J Econ 26:537-556

Botteon M, Carraro C, (1997) Environmental coalitions with heterogeneous countries: Burden-sharing and carbon leakage. Fondazione Eni Enrico Mattei Working Paper, Fondazione Eni Enrico Mattei Working Paper

Bouma JA, Nguyen TTB, van der Heijden E, Dijk JJ (2020) Analysing group contract design using a threshold public goods experiment. Eur Rev Agric Econ 47:1250-1275

Brau R, Carraro C (2011) The design of voluntary agreements in oligopolistic markets. J Regul Econ 39:111-142

Busby GM, Albers HJ, Montgomery CA (2012) Wildfire risk management in a landscape with fragmented ownership and spatial interactions. Land Econ 88:496-517 
Carraro C, Marchiori C, (2002) Stable Coalitions (SSRN Scholarly Paper No. ID 299624). Social Science Research Network, Rochester, NY

Carraro C, Siniscalco D (1993) Strategies for the international protection of the environment. J Public Econ 52:309-328

Chander P, Tulkens H (1997) The core of an economy with multilateral environmental externalities. Intern J Game Theory 26:379-401

Cong R-G, Smith HG, Olsson O, Brady M (2014) Managing ecosystem services for agriculture: will landscape-scale management pay? Ecol Econ 99:53-62

Constant N, Lernould J, (2014) La gestion de la Flavescence dorée en viticulture biologique. Institut français de la vigne et du vin

Costello C, Quérou N, Tomini A (2017) Private eradication of mobile public bads. Eur Econ Rev 94:23-44

d'Aspremont C, Jacquemin A, Gabszewicz JJ, Weymark JA, (1983) On the stability of collusive price leadership. Can J Econ 17-25

Drechsler M (2017) The impact of fairness on side payments and cost-effectiveness in agglomeration payments for biodiversity conservation. Ecol Econ 141:127-135

Dupraz P, Latouche K, Turpin N (2009) Threshold effect and co-ordination of agri-environmental efforts. J Environ Plan Manag 52:613-630

Epanchin-Niell RS, Wilen JE (2015) Individual and cooperative management of invasive species in human-mediated landscapes. Am J Agr Econ 97:180-198

Finus M, McGinty M (2019) The anti-paradox of cooperation: diversity may pay! J Econ Behav Organ 157:541-559

Franks JR (2019) An assessment of the landscape-scale dimensions of land based environmental management schemes offered to farmers in England. Land Use Policy 83:147-159

Gallai N, Salles J-M, Settele J, Vaissière BE (2009) Economic valuation of the vulnerability of world agriculture confronted with pollinator decline. Ecol Econ 68:810-821

Gengenbach MF, Weikard H-P, Ansink E (2010) Cleaning a river: an analysis of voluntary joint action. Nat Resour Model 23:565-590

Haines-Young R, Potschin M (2010) The links between biodiversity, ecosystem services and human well-being. In: Raffaelli D, Frid C (eds) Ecosystem ecology: a new synthesis. Cambridge University Press, pp 110-139

Hanley N, Breeze TD, Ellis C, Goulson D (2015) Measuring the economic value of pollination services: principles, evidence and knowledge gaps. Ecosyst Serv 14:124-132

Heckelei T, Wolff H (2003) Estimation of constrained optimisation models for agricultural supply analysis based on generalised maximum entropy. Eur Rev Agric Econ 30:27-50

Kotchen MJ, Segerson K (2019) On the use of group performance and rights for environmental protection and resource management. Proc Natl Acad Sci 116:5285-5292

Lonsdorf E, Kremen C, Ricketts T, Winfree R, Williams N, Greenleaf S (2009) Modelling pollination services across agricultural landscapes. Ann Bot 103:1589-1600

Moran PAP (1948) The Interpretation of statistical maps. J R Stat Soc Ser B Methodol 10:243-251

Olson M (1965) The logic of collective action. Harvard University Press

Orazem PF, Miranowski JA (1994) A dynamic model of acreage allocation with general and crop-specific soil capital. Am J Agr Econ 76:385-395

Osmani D, Tol RSJ (2010) The case of two self-enforcing international agreements for environmental protection with asymmetric countries. Comput Econ 36:93-119

Pasher J, Mitchell SW, King DJ, Fahrig L, Smith AC, Lindsay KE (2013) Optimizing landscape selection for estimating relative effects of landscape variables on ecological responses. Landscape Ecol 28:371-383

Punt MJ, Wesseler J (2018) The formation of GM-free and GM coasean clubs: will they form and if so how much can they achieve? J Agric Econ 69:413-438

Sáiz ME, Hendrix EMT, Olieman NJ (2006) On the computation of stability in multiple coalition formation games. Comput Econ 28:251-275

Silva JCDV, Aragão AKO (2008) Production costs and fruit yield profitability in the initial harvest of custard apple trees. Revista Brasileira de Fruticultura 30:931-939

Therond O, Tichit M, Tibi A (2017) Volet" écosystèmes agricoles" de l'Evaluation Française des Ecosystèmes et des Services Ecosystémiques. Rapport d'étude, Inra (France)

Thomas A (2003) A dynamic model of on-farm integrated nitrogen management. Eur Rev Agric Econ 30:439-460

Vogt C (2016) Climate coalition formation when players are heterogeneous and inequality averse. Environ Resour Econ 65:33-59 
Weikard H-P, Wangler L, Freytag A (2015) Minimum participation rules with heterogeneous countries. Environ Resour Econ 62:711-727

Willinger M, Ammar N, Ennasri A (2014) Performance of the ambient tax: does the nature of the damage matter? Environ Resour Econ 59:479-502

Zavalloni M, Raggi M, Viaggi D (2019) Agri-environmental policies and public goods: an assessment of coalition incentives and minimum participation rules. Environ Resour Econ 72:1023-1040

Zhang W, Ricketts TH, Kremen C, Carney K, Swinton SM (2007) Ecosystem services and dis-services to agriculture. Ecol Econ 64:253-260

Zhou R, Segerson K (2016) Individual vs. collective approaches to fisheries management. Mar Resour Econ 31:165-192

Zurbuchen A, Landert L, Klaiber J, Müller A, Hein S, Dorn S (2010) Maximum foraging ranges in solitary bees: only few individuals have the capability to cover long foraging distances. Biol Cons 143:669-676

Publisher's Note Springer Nature remains neutral with regard to jurisdictional claims in published maps and institutional affiliations. 